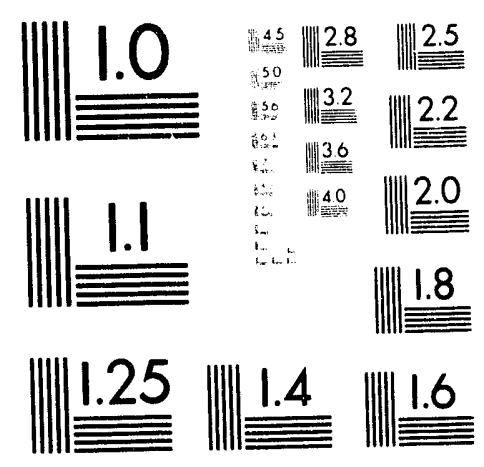



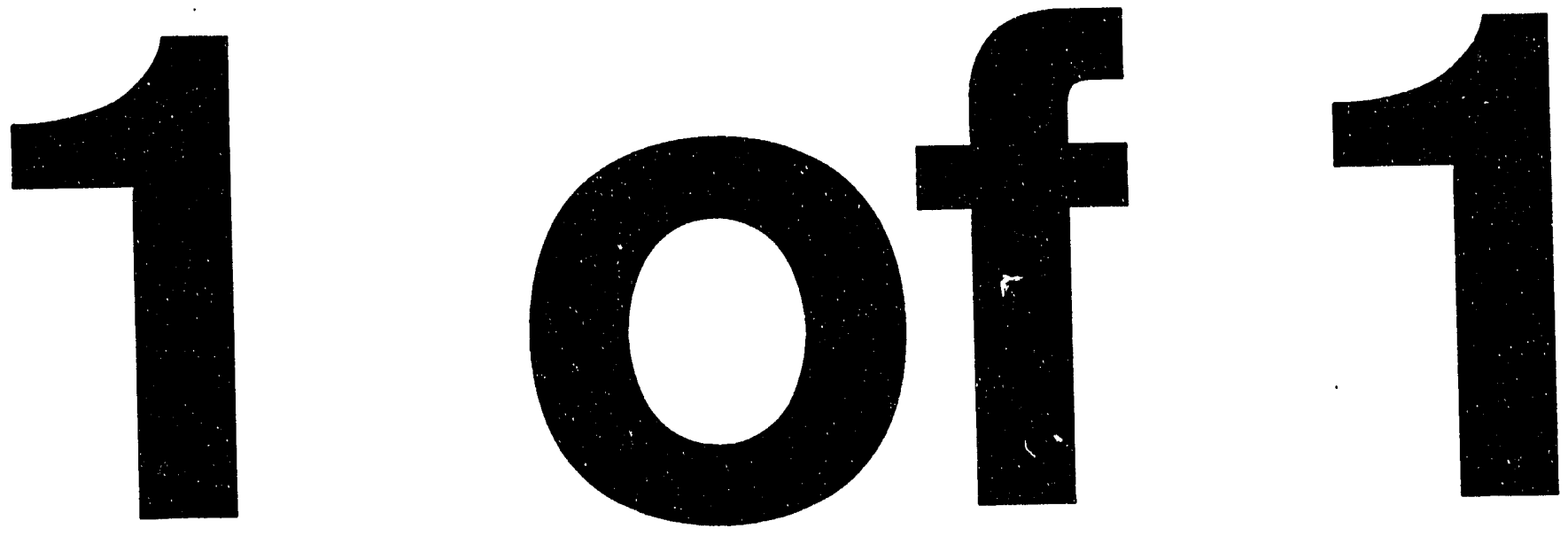
Single-Point Representative Sampling with Shrouded Probes

Andrew R. McFarland*

John C. Rodgers 
TABLE OF CONTENTS

Figures

vii

ABSTRACT

1

EXECUTIVE SUMMARY

PART 1: REGULATIONS AND PROPOSED ALTERNATE METHODS

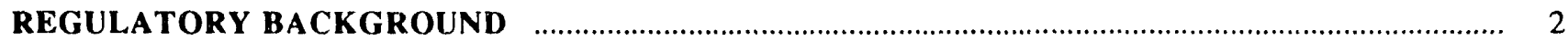

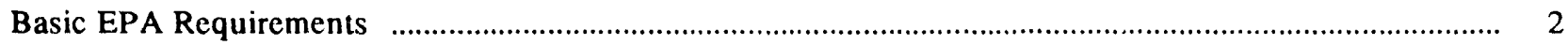

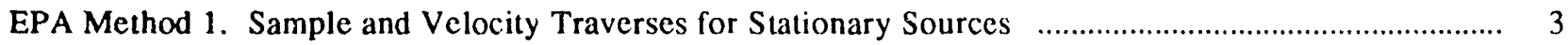

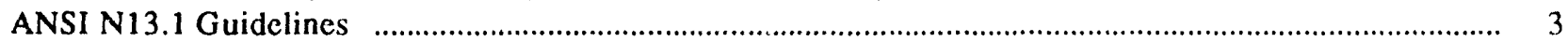

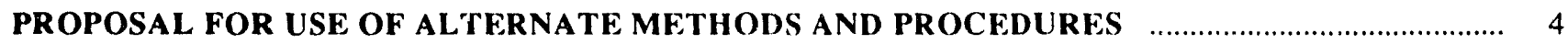

PART 2: TECHNICAL JUSTIFICATION

INTRODUCTION

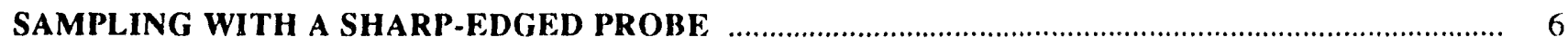

MODELING ASPIRATION RATIOS OF SHARP-EDGED SAMPLING PROBES ................................ 7

WALL LOSSES IN ISOKINETIC SAMPLING PROBES . ............................................................ 8

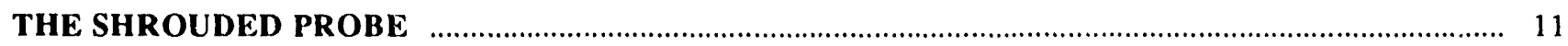

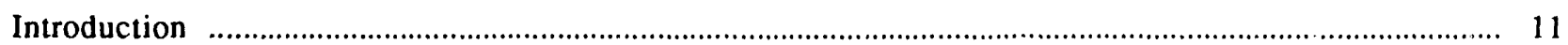

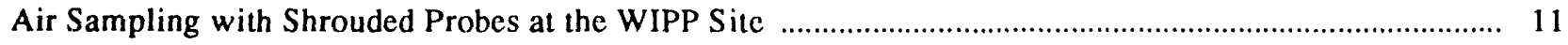

The Principle of Operation of a Shrouded Probe …............................................................................. 13

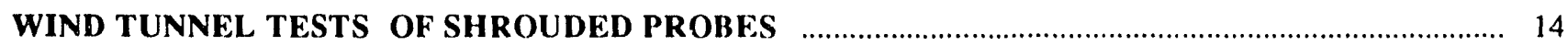

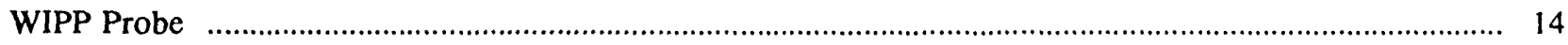

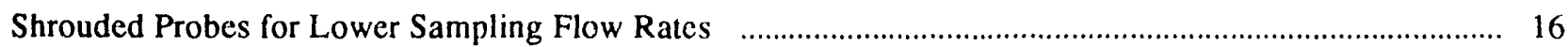

Effects of Wind Speed and Particle Size

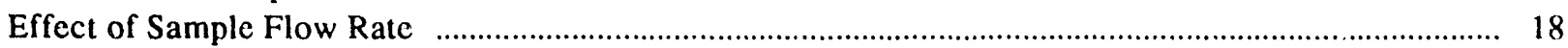

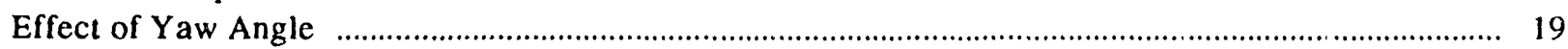

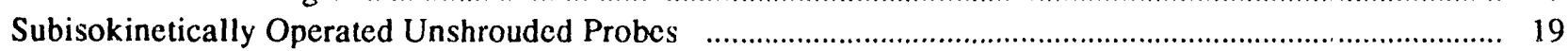

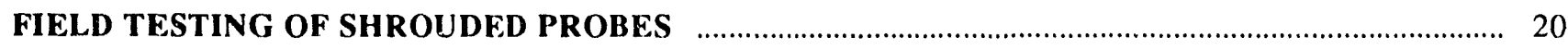

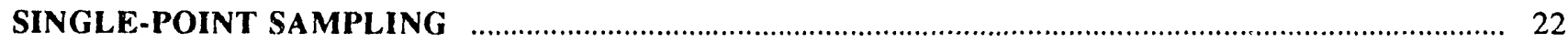

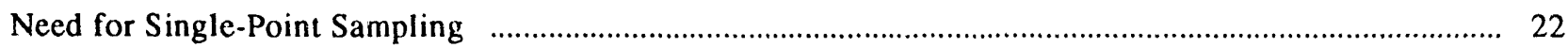

Selection of Suitable Locations for Single-Point Sampling f ................................................................. 23

Verification of Suitability of a Single-Point Sampling Location ........................................................... 23

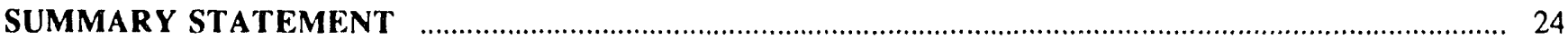

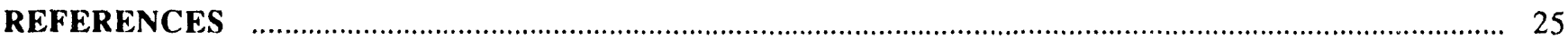




\section{FIGURES}

1. Illustration of sampling with a sharp-edged probe.

2. Anisokinetic errors caused by changes in the free stream velocity for a probe designed to be isokinetic at $21.3 \mathrm{~m} / \mathrm{s}(70 \mathrm{ft} / \mathrm{s})$.

3. Sharp-edged probes recommended by ANSI (1969) for (a) single-point and (b) multipoint sampling. ........ 9

4. An ANSI-type probe from a nuclear facility that was tested for wall losses in a wind tunnel. ..................... 9

5. Internal wall losses for iscikinetic operation of the ANSI-type probe of Fig. 4. .......................................... 9

6. Probe design recommended by the American Society of Mechanical Engineers (ASME 1980).................... 10

7. Isokinetic probe design recommended by Farthing and Dawes (1988) for use with source-testing cyclones.

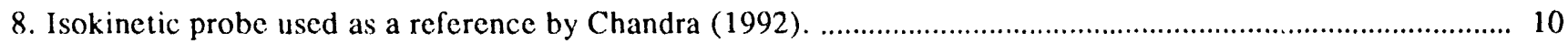

9. Internal wall losses in the Chandra unshrouded probe............................................................................ 11

10. Shrouded probe used for sampling in the mine ventilation exhaust ducts at the WIPP site........................... 12

11. Illustration of the principle of operation of a shrouded probe aerosol sampler. .......................................... 13

12. Computer model of the flow streamlines in and about a shrouded probe. ..................................................... 14

13. Velocity profiles at various locations along the centerline of a shrouded probe. ......................................... 15

14. Transmission ratio, $\mathrm{T}$, and aspiration ratio, $\mathrm{A}$, of the WIPP probe. ........................................................ 15

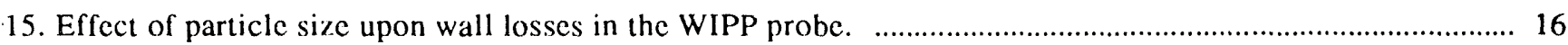

16. Shrouded probe tested by Chandra (1992) in acrodynamic and acrosol wind tunnels. ................................. 16

17. Comparison of wall losses in sharp-edged isokinetic and shrouded probes

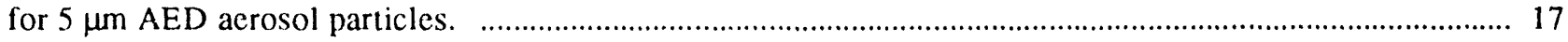

18. Comparison of wall losses in sharp-edged isokinetic and shrouded probes

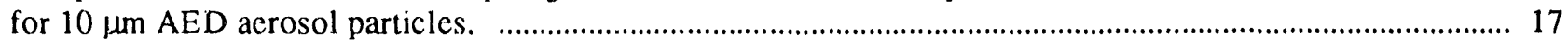

19. Comparison of wall losses in sharp-edged isokinetic and shrouded probes for $15 \mu \mathrm{m}$ AED acrosol particles.

20. Comparison of transmission ratios of sharp-edged isokinctic and shrouded probes for $5 \mu \mathrm{m}$ AED acrosol particles.

21. Comparison of transmission ratios of sharp-edged isokinetic and shrouded probes for $10 \mu \mathrm{m}$ AED acrosol particles.

22. Comparison of transmission ratios of sharp-edged isokinetic and shrouded probes for $15 \mu \mathrm{m}$ AED acrosol particles.

23. Variation of aspiration ratio of a shrouded probe with free stream velocity.

24. Changes in the transmission ratio of a shrouded probe with variations in sampling flow rate for $10 \mu \mathrm{m}$ AED acrosol particles.

25. Effect of yaw angle upon performance of a shrouded and an unshrouded probe.

26. Performance of a nonshrouded, sharp-edged probe operated with various degrees of subisokineticity.

(a) Transmission ratio. (b) Wall loss ratio.

27. Layout of apparatus used by WIPP to test the shrouded probes installed at the exit of the main mine-ventilation duct.

28. Relationship between the number of isokinetic probes and wall losses. 


\title{
SINGLE-POINT REPRESENTATIVE SAMPLING WITH SHROUDED PROBES
}

\author{
by \\ Andrew R. McFarland and John C. Rodgers
}

\begin{abstract}
The Environmental Protection Agency (EPA) prescribed methodologies for sampling radionuclides in air effluents from stacks and ducts at US Department of Energy (DOE) facilities. Requirements include use of EPA Method 1 for the location of sampling sites and use of American National Standards Institute (ANSI) N13.1 for guidance in design of sampling probes and the number of probes at a given site. Application of ANSI N13.1 results in sampling being performed with multiprobe rakes that have as many as 20 probes. There can be substantial losses of aerosol particles in such sampling that will degrade the quality of emission estimates from a nuclear facility. Three alternate methods, technically justified herein, are proposed for effluent sampling. First, a shrouded aerosol sampling probe should replace the sharp-edged elbowed-nozzle recommended by ANSI. This would reduce the losses of aerosol particles in probes and result in the acquisition of more representative aerosol samples. Second, the rakes of multiple probes that are intended to acquire representative samples through spatial coverage should be replaced by a single probe located where contaminant mass and fluid momentum are both well mixed. A representative sample can be obtained from a well-mixed flow. Soms imlent flows will need to be engineered to achieve acceptable mixing. Third, sample extraction should be performed at a constant flow rate through a suitable designed shrouded probe rather than at a variable flow rate through isokinetic probes. A shrouded probe is shown to have constant sampling characteristics over a broad range of stack velocities when operated at a fixed now rate.
\end{abstract}

\section{EXECUTIVE SUMMARY}

Under the Environmental Protection Agency (EPA) radionuclide air emission standards for Department of Energy (DOE) facilities, $40 \mathrm{CRF} 61$, representative sampling of stacks and ducts is to be done following the guidance of the American National Standards Institute (ANSI) standard number N13.1 at sampling sites selected using EPA Methed 1. However, the EPA regulations allow other approaches to be used if it is impractical to follow these methods. The ANSI standard specifies the design of the sampling probes and it provides recommendations on the number of sampling points; but, it permits fewer sampling points to be used if it can be shown that the effluent flow is fully mixed at the sample extraction point. Here we propose to use singlepoint sampling for sampling situations in which contaminant concentration and fluid momentum are both well mixed. In addition, we propose to use shrouded probes to accomplish the single-point sampling.

At the time the ANSI standard was adopted (1969), the limitations of isokinetic probes were not realized and the 
ANSI committec recommended universal usage of isokinetic sampling in stacks and ducts. Currently, this standard is undergoing revision and it appears that the new version of the standard will not require isokinetic sampling.

The transmission ratio, $T$, is the most important performance characteristic of a probe that is used to continuously sample radioactive aerosol particles, where $T$ represents the ratio of aerosol concentration at the probe exit plane to the aerosol concentration in the free stream. For isokinetic sampling, the ideal value of $T$ is unity; however, due to losses of particles on the internal walls of isokinetic probes, it will be less than unity. Indeed, in wind tunnel experiments that simulate stack sampling with ANSI-type isokinetic probes, the transmission ratio is about $20 \%$ to $40 \%$ for $10 \mu \mathrm{m}$ aerodynamic equivalent diameter (AED) particles over a range of free stream velocities of 6 to $20 \mathrm{~m} / \mathrm{s}$. For an isokinetic probe that has improved design characteristics, the transmission ratio is about $60 \%$. By comparison, a shrouded probe typically has a transmission ratio of $80 \%$ to $110 \%$ for the same range of conditions. Besides having a better transmission ratio, a shrouded probe can accommodate off-design operational conditions hetter than an isokinetic probe. If the free stream velocity in a stack were to change, it would affect the performance of the shrouded probe less than it would affect an isokinetic counterpart. Similarly, if the flow rate through the probe were to change, the transmission ratio of the shrouded probe would not be affected as significantly as that of the isokinetic probe. Also, if there is a non-zero angle between the directions of the probe axis and the free stream velocity vectors, such as would be caused by flow swirl or large-scale free stream turbulence, the shrouded probe has better aerosol sampling characteristics.

For single-point sampling to be applicable, there must not be abnormal inhomogeneities in contaminant concentration or fluid momentum (i.e., the concentration and velocity profiles must be relatively uniform) in the region where sampling takes place. EPA, under its Method 1, uses an 8-and 2-rule for assurance that flow inhomogeneities are acceptable, where the rule suggests that sampling should be performed at a distance of at least 8 duct diameters downstream from a disturbance (elbow, contraction, tee, etc.) and at least 2 diameters upstream from a disurhance. The EPA rule of thumb does not accurately reflect the most suitable locations for sampling. If a contaminant is introduced at the center of a long straight pipe, 50 duct diameters may be required for the contaminant to hecome distributed across the pipe; yet, if a double eibow is used upstream of the sampling location, only 4 diameters may he needed to uniformize the concentration profile. Similarly, the use of a static mixer in a flow stream will provide homogeneous concentration and velocity profiles at a distance of perhaps 3 diameters from the mixer. Also, wind tunnel and field tests have shown that under certain circumstances, accurate aerosol sampling can be done within 1.5 diameters of a downstream disturbance.

The approach that we will employ to demonstrate the suitability of location in a stack for single-point sampling will involve first analyzing the flow arrangement to estimate the mixing at a candidate location. If it appears suitable, the location will be tested with tracers to characterize the concentration profile and with the EPA Method 2 protocol to establish the velocity profile. If either the initial analysis does not suggest satisfactory mixing (but yet the site must be used because of other constraints) or if the site initially appeared suitable, but tests show either the coefficient of variation of concentration or velocity to be greater than $20 \%$ over the center $2 / 3$ of the duct, the flow will be engineered to improve mixing. Tests will be conducted to verify the acceptability of the mixing.

\section{PART 1:}

\section{REGULATIONS AND PROPOSED ALTERNATE METHODS}

\section{REGULATORY BACKGROUND}

\section{Basic EPA Requirements}

Under 40 CFR 61, Subpart H, "National Emission Standards for Emissions of Radionuclides Other Than Radon from Department of Energy Facilities," (a part of the National Emissions Standards for Hazardous Air Pollutants, or NESHAPs), the US EPA has recommended apparatus and methods for characterizing the emissions of particles and gases from stacks and vents (US EPA 1991a). For the present consideration, the important relevant statements in the standard are the following:

“\$61.93(b) Radionuclide emission rates from point sources (stacks or vents) shall be measured in accordance with the following requirements or other procedures for which EPA has granted prior approval." 
"\$61.93(b)(2)(i) Reference Method 1 of Appendix A Part 60 shall be used to select monitoring or sampling sites."

" $\$ 61.93(b)(2)(i i)$ The effluent stream shall be directly monitored with an in-line detector or representative samples of the effluent stream shall be withdrawn continuously from the sampling site following the guidance presented in ANSI N13.1 'Guide to Sampling Airborne Radioactive Materials in Nuclear Facilities' (including the guidance presented in Appendix $A$ of ANSI N13.1)."

" $\$ 61.93(3)$ When it is impractical to...monitor or sample an effluent stream at an existing source in accordance with the site selection and sample extraction requirements of paragraph (b)(2), the facility owner or operator may use alternative... site selection and sample extraction procedures provided that:

(i) It can be shown that the requirements of paragraph ...(b)(2) of this section are impractical for the effluent stream.

(ii) The alternative procedure will not significantly underestimate the emissions.

(iii) The alternative procedure is fully documented.

(iv) The owner or operator has received prior aproval from EPA."

\section{EPA Method 1. Sample and Velocity Traverses for Stationary Sources}

Method 1 of the EPA standard essentially provides guidance on the selection of the sampling site, and it provides rules for the location of points in the flow stream where velocity values are to be measured and the points where aerosol samples are to be collected. However, it appears that the number of sampling points specified in Method 1 is made moot by the recommendations of ANSI N13.1.

The important section of Method 1 related to the present discussion is:

2.I Selection of Measurement Site. This section contains the "8- and 2-diameter" rule, which states that sampling should be conducted at locations that are at lcast 8 stack diameters downstream and 2 diameters upstream from any flow disturbance. Studies have shown that this rule does not provide suitable guidance for flow mixing under a surprisingly large range of conditions (Fasano 1991; Hampl et al. 1986; Tasucher and Streiff 1979; Turner et al. 1989). Other selection criteria should be used.

\section{ANSI N13.1, Guidelines}

ANSI N13.1, Guide to Sampling Airborne Radioactive Materials in Nuclear Facilities, was adopted in 1969, and as such, it does not include the body of knowledge that has been acquired in the past 23 years. The standard is currently undergoing revision, and it appears that several provisions of the standard will be modified (Glissmeyer 1992; McFarland et al. 1992). Aspects of the 1969 version of the ANSI standard that are of consequence to singlepoint representative sampling are:

Introduction, Definition, and Principles. The standard, in these sections, stresses the importance of sampling in a way that shows the quality and characteristics of the entire volume from which the sample is drawn. Accordingly, a sampler must not fractionate by particle size or otherwise distort the properties of radioactive constituents. It will be shown that single-point representative sampling meets this principle.

Appendix 4.2.2.3. Particle Size Fractionation Due to Anisokinetic Sampling. A recommendation is given for isokinetic sampling when particles larger than $5 \mu \mathrm{m}$ are anticipated. The standard states that isokinetic sampling will avoid a potential source of non-representative sampling.

We believe the value of isokinetic sampling is overstated. As we will demonstrate in this report, errors due to internal wall losses in probes are much more significant than anisokinetic errors in a typical stack sampling application. More representative samples can be obtained with a probe placed inside of an anisokinetically operated shroud than can be obtained with ANSI-type isokinetic probes.

Appendix A.3.2. Withdrawal Points in the Cross Section to Assure a Representative Sample. In this section of the standard, specific numerical guidance is provided for the number of withdrawal points needed to achieve representative sampling. The most serious drawback from the sampling perspective is the degraded sample extraction performance of multiprobe designs that conform to these numerical guides. Also, a typical velocity profile in a stack will usually preclude simultaneous isokinetic sampling at all points on a multiprobe rake (i.e., probe inlet velocities will not match the actual profile velocities at many, or most, of the extraction points. The concept employed in 40 CFR 61 is that a representative sample can be acquired through simultaneous collection of aerosol at several points. 
This is an extension of the approach used successfully by EPA in its non-nuclear Method 5 sampling (1991c). However, there are significant differences between the Method 5 approach and that required by 40 CFR 61 , Subpart $\mathrm{H}$, for nuclcar applications. In Method 5 , a single probe is used to sequentially sample at the prescribed points in a stack during a test that typically is completed within a few hours. Such tests are conducted periodically, c.g., once a year. Acrosol particles that are inadvertently deposited in the probe or transport tubing are extracted by a washing procedure at the completion of a test. To carry out the continuous sampling in nuclear applications, multiple probes are normally required. For circular ducts with diameters greater than $2 \mathrm{ft}, 4$ to 6 probes are recommended, and for rectangular ducts with areas greater than $2 \mathrm{ft}^{2}, 6$ to 20 probes are recommended. These probes are usually mounted on a manifold called a rake. A multiprobe rake is sometimes called an "instantancous traverse," but that term is highly misleading.

The sampling approach recommended for nuclear applications causes the representative nature of samples to be degraded relative to EPA non-nuclear stack sampling. Internal wall losses in sampling probes increase as the number of probes is increased, so the benefits of "instantancous traverse" largely become illusionary. The wall losses in continuously operated nuclear sampling probes cannot be extracted as can losses that occur in Method 5 stack tests.

It is important to note the guidelines of the ANSI standard provide that fewer sampling points can be used if it can be shown that the cencentration and velocity profiles are well developed at the sampling location.

Appendix A.3.4. Sampling Probe Configurations. Guidance is provided for the design of sharp-edged probes and multinozzle rakes of such sharp-edged probes. The standard does acknowledge that aerosol deposition can be significant in particular applications. Recent studies have shown that there are scrious limitations in the recommendation for use of sharp-edged probes and that some of the probe losses are intrinsic. The use of rakes compounds the problem of aerosol losses in probes. Superior performance can be achieved with simpler designs.

\section{PROPOSAL FOR USE OF ALTERNATE METHODS AND PROCEDURES}

As we shall show in this document, it is impractical to continuously monitor or sample radionuclide-containing stack or duct flows by following the methodology and guidance specified in EPA Method 1 and ANSI N13.1. A representative sample cannot be obtained due to severe internal wall losses of acrosol particles that occur because of employment of a large number of ANSI-type probes. Therefore, pursuant to $\$ 61.93$ (b)(3)(i) of $40 \mathrm{CRF} 61$, a request is to be made to the administrator of EPA to approve single-point representative sampling with a shrouded probe when it can be shown that the velocity and concentration (acrosol and gas) profiles are well developed by turbulent mixing at the sample withdrawal plane.

Specifically, there are three elements in our proposed Alternate Methods:

1) For aerosol sampling, it will be proposed that a suitably designed shrouded probe can replace the ANSI probe design;

2) It will be proposed that the requirement for multiprobe rakes, which includes a provision for larger numbers of withdrawal points for larger stack diameters, can be replaced with a requirement that the concentration and velocity profiles are both sufficiently well developed at the sample withdrawal location to allow sample extraction from a single point in the flow regardless of the diameter of the stack; and

3) Sample extraction through a suitably designed shrouded probe at a fixed design flow rate is an acceptable alternative to "isokinctic sampling," wherein for the latter approach, the 'ample flow rate is adjusted to such a rate as to cause the probe inlet velocity to match the free stream velocity.

These three elements are discussed further and are shown to be amply justificd on technical grounds in the following sections. It is recognized that these proposed alternate methods impose demands on the engineering of complete mixing in stacks as a precondition to singlepoint sampling. However, it is our contention that this should always be a precondition of sampling whatever the number of nozzles and that the alleged benefits of the "instantaneous traverse" are largely illusory.

The requirements for representative sampling at Los Alamos National Laboratory are described in the document, "Representative Sampling and Monitoring of Airborne Radioactive Effluent at Los Alamos National Laboratory" (Rodgers 1992). The present document provides supporting evidence of the acceptability of the single-point sampling method and the use of shrouded probes proposed in that document. Single-point sampling in stacks and ducts, where it is demonstrated the 
composition is uniform, is in accordance with the guidelines of ANSI N13.1 Seciion A.3.2. Here we interpret the word composition to refer to aerosol and gas concentration; and we interpret the word uniform to mean well-mixed (it is physically impossible to have periectly uniform velocity and concentration profiles).

Under the proposed altermative methodologies, we would use EPA Mett ds 1 and 2 (or $2 C$ ) to demonstrate the uniformity of the velocity profile, and we would use tracer gas and acrosol methods to show the rititormity of the concentration profiles. We propose to use a criterion for acceptability of concentration profiles similar to that given in an EPA standard for testing ambient aerosol sampling devices in wind tunneis, 40 CRF 53.42(c), for which the EPA criterion essentially requires that the concentration be within $\pm 10 \%$ over a sampling region. For stacks and ducts, we suggest a criterion that is defined in terms of the coefficients of variation (COVs) of the normalized concentration and velocity profiles. Those COVs must be within $\pm 20 \%$ over the center $2 / 3$ of the stack or duct for the mixing to be considered acceptable such that a location could he used for single-point sampling (Rodgers 1992). To preclude the possibulity of high concentrations outside of the center $2 / 3$ of the stack or duct, we propose that any point on an 8 to 12 point EPA Method 1 grid, the concentration shall not exceed the mean concentration by more than $30 \%$.

As required by 40 CRF $61.93(\mathrm{~h})(3)(\mathrm{i})$, an alternate sampling procedure must not underestimate the emissions. With respect to emission estimates for aerosols resulting from use of the shrouded probe to achieve single-point representative sampling, the proposed alternate method will yicld values that are both more accurate and of magnitudes that are greater than or equal to those determined with ANSI probes. For gases, the proposed method will yield estimates that are the same as those obtained with ANSI apparatus.

\section{PART 2:}

\section{TECHNICAL JUSTIFICATION}

\section{INTRODUCTION}

In the nuclear industry, air samples from stacks and ducts are used to either provide near-real time warnings if levels of radionuclide air emissions should exceed facility limits or to provide retrospective integrated samples of air emissions. Compliance of a DOE facility with the dose requirements of 40 CRF 61, Subpart $H$ is based on representative samples of all air emissions during facility operation.

It is important in nuclear applications involving radioactive acrosol sources that sampling probes are designed well to minimize the losses of particulate matter, because for retrospective samplers (called filter air samplers or FAS systems), losses produce an underestimation of the concentration of radionuclides, and for near-real time samplers (known as continuous air monitors or CAM systems), the losses reduce the effectiveness of alarming capabilities. This requirement contrasts with the requirement for source testing of nonnuclear stacks in which aerosol inadvertently deposited in a probe and transport system during grab sampling is recovered at the completion of each test hy washing all inside surfaces of the probe and acrosol transport tubes (US EPA 199/c). In continuous monitoring of radionuclides, there is no realistic opportunity to recover particles lost on the internal walls of a sampling system

In the following sections of this technical document, we will discuss the aspiration of aerosols into probes and the sample bias caused by intrinsic characteristics of sharp-edged probes. With isokinetic operation there are losses of particles to the internal walls of a probe, and we will present experimental evidence that illustrates the magnitude of wall losses and an understanding of what causes these wall losses. The internal losses in a probe can he reduced through use of certain design principles. We will show the methodology for effecting this reduction.

Wall losses are based on the assumption that particles have unity attachment coefficients. i.c., upon contact, they stick to a surface. Experimentally, data on wall losses are gathered with liquid acrosol particles that adhere to surfaces. In contrast, large-sized solid particles may bounce from surfaces, particularly at high speed. Because of the uncertainty in characterizing losses with solid particles, which have attachment coefficients that depend upon a large number of variables (surface and particle composition, relative humidity, particles speed and angle of approach, parti-le size, etc.), we have chosen to use liquid particle data. This app:oach provides conservalive estimates of acrosol particle transmission through sampling systems.

The particle size that we will typically use in examples is $10 \mu m$ acrodynamic equivalent diameter (AED). Air from nuclear stacks and ducts that vent to the atmosphere is generally (HEPA) filtered, so under normal conditions 
there would be no large particles. Pursuant to the requirements of ANSI N13.1 that states adequate samples must be obtained during accidental releases, we must assume that the integrity of the HEPA filters could be violated and that sipramicrometer acrosol particles would be released. The size of $10-\mu \mathrm{m}$ AED is selected brcause those particles can be transported substantial distances from the source and they can ise inhaled into the thoracic region of the human respiratory system. EPA has selected 10- $\mu \mathrm{m}$ AED as the size that is used in ambient air sampling instruments to separate the noninhalable from inhalable particles (US EPA 1987).

\section{SAMPLING WITH A SHARP-EDGED PROBE}

Operation of an acrosol probe in a stack or duct is usually explained through the concept of isokinetic and anisokinetic sampling as illustrated in Fig. 1. For isokinctic sampling (Fig. 1a), a sharp-edged probe is aligned isoaxially with the undisturbed flow streamlines, where the term undisturbed refers to the straight streamlines upstream of the probe. The spatial mean velocity at the inlet plane of the probe, $U_{i}$, is matched to the temporal mean velocity of the undisturbed air flow upstream of the probe, $U_{\infty}$. Anisokineticity can occur if the velocity at the entrance of the probe is less than that of the free stream (i.c., $U_{i}<U_{\infty}$ ), a condition that is called subisokinetic sampling (Fig. 1b); or if the velocity at the entrance plane of the probe exceeds that of the free stream $\left(U_{i}>U_{\infty}\right)$, which is called superisokinctic sampling (Fig. 1c).

An erroncous perception is created by using the approach illustrated in Fig. 1 to explain the proper design of acrosol sampling probes for stacks and ducts; namely, there is an implication that isokinctic sampling through sharp-edged proses is perfect sampling that can only be flawed by anisokinetic effects. However, we wish to emphasize that isokinctic sampling through such a probe is inherently flawed by unavoidable internal wall losses in the probe inlet region.

The aspiration ratio, $A$, of a sampling probe is the ratio of mean particle concentration across the probe entrance plane to the particle concentration in the free stream:

$$
A=\frac{c_{i}}{c_{\infty}}
$$

where $c_{i}=$ spatial mean concentration at the probe inlet plan: and $c_{\infty}=$ concentration in the free stream. The

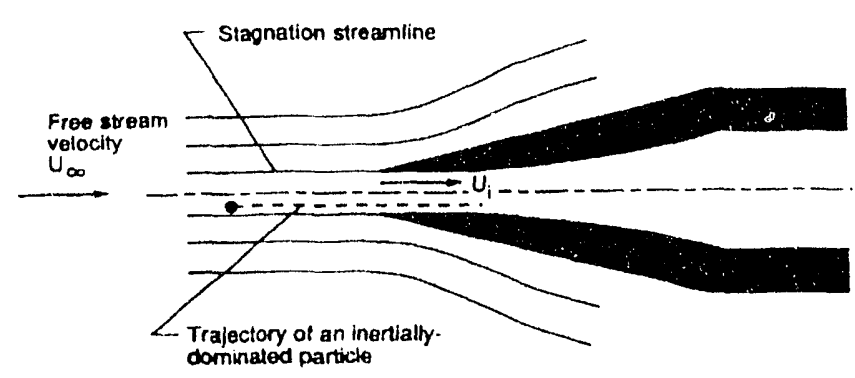

a) Isokinetic Operation

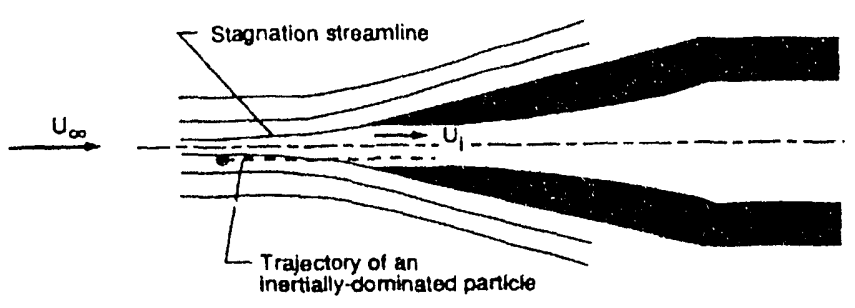

a) Subisokinetic Operation

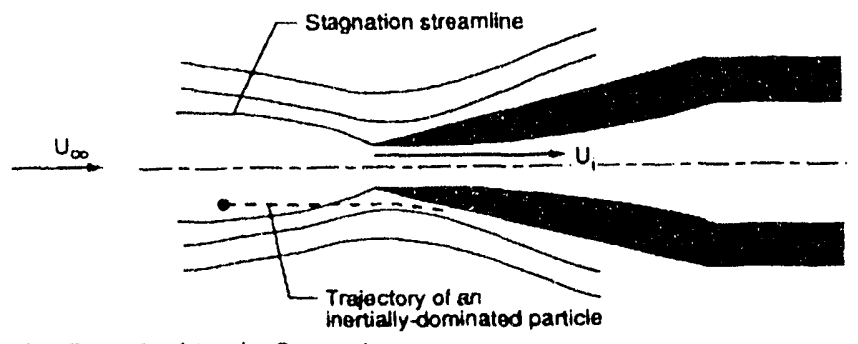

b) Superisokinetic Operation

Fig. 1. Illustration of sampling with a sharp-edged probe. Isokinetic sampling (a) is thought of as ideal sampling; however, it does not take into account internal wall losses in a probe. With nonisokinetic sampling $(b, c)$ the aspiration ratio is nonunity.

value of $A$ is unity for isokinetic sampling. As we shall note, it is the transmission of aerosol particles through the probe to the transmission line or filter rather than the aspiration ratio, $A$, that is the more important performance factor in nuclear aerosel sampling applications.

The transmission ratio, $T$, is the ratio of aerosol concentration at the probe exit plane, $\mathrm{c}_{\mathrm{e}}$, to the aerosol concentration in the free stream:

$$
T=\frac{c_{e}}{c_{\infty}}
$$


It is the transmission ratio that quantifies the amount of aerosol delivered by a probe to a sampler or transport system. The wall loss ratio in a probe, $W l$, is the ratio of the equivalent aerosol concentration deposited on the internal walls of the probe to the acrosol concentration at the probe entrance plane. Aspiration ratio, transmission ratio, and wall 'oss ratio are related by:

$$
T=A(1-W l)
$$

The wall loss ratio is always positive; thus, the transmission ratio will always be smaller than the aspiration ratio.

When sampling takes place subisokinetically (Fig. 1b), there can be inertial enrichment of aerosol into the inlet from streamlines that pass around the inlet, which can cause the aspiration ratio to be greater than unity. Under certain subisokinetic conditions, the transmission ratio can also be greater than unity, provided the wall losses are sufficiently small. With respect to superisokinetic sampling, the convergence of the flow streamlines into the inlet creates a condition of inertial depletion of aerosol concentraiin from the outer stream.lines that enter the probe thereby causing both the aspiration and transmission ratios to be less than unity.

There is an additional anisokinetic effect that should be considered, namely, that which occurs when the probe axis and the free stream velocity are not parallel. Let $\theta$ represent the angle between the stream velocity and the probe axis. For sampling under conditions in which $\theta \neq 0^{\circ}$ the aspiration ratio, $A$, can be reduced below unity by both inertial effects (particles tending to go straight rather than turning to enter the probe) and by the geometric consideration that the projected entrance area varies with $\cos \theta$.

Although at first thought it would seem that isokinetic operation of a probe would be a simple matter to achieve both from the standpoints of maintaining $U_{i}=U_{\infty}$ and $\theta=0^{\circ}$, the realities of the actual sampling process make it difficult to maintain the isokinetic condition. First, with respect to the equal velocity condition, problems are imposed by the fact that most CAM and FAS units are setup to operate with approximately constant sampling flow rates. However, a sampling flow rate can change because of a number of factors, including the buildup of a dust deposit on the surface of the sampling filter. In practice, the flow rate through many CAM and FAS samplers is maintained by the pressure level in a vacuum source rather than held at a fixed rate by a flow controller. If the vacuum level changes, the flow rate through the sampler will change. In addition, there can be changes in the free stream velocity with time resulting from changing conditions in facility use. For example, the flow rate through a stack at Los Alamos National Laboratory was measured annually over a 3 -year period. The results showed the flow rate ranged from 47,000 to $54,000 \mathrm{cfm}$ (with a proportional variation in the mean velocity in the stack). Also, the velocity profile in a stack is usually not uniform, which makes it unlikely that each probe on a rake will be subjected to the same free stream velocity. If the flow rate is constant through each probe, many probes will be operated at varying degrees of anisokineticity.

There are two problems associated with attempting to achieve and maintain the isoaxial condition $\left(\theta=0^{\circ}\right)$. First, the simplistic approach for illustrating isokinetic sampling in Fig. 1 neglects the effects of turbulence. Typically, air flows in stacks and ducts are highly turbulent with temporal root mean square off-axis velocity components being on the order of several percent of the mean velocity. Off-axis velocity components that are associated with turbulent eddies will cause random off-axis sampling events. In addition to causing the angle $\theta$ to undergo fluctuations, turbulence also causes wall losses in the probe inlet to increase (Weiner et al. 1988; Gong et al. 1993). Second, there is often swirl in the stack flow that creates a non-zero angle between a probe and the fluid streamlines. One approach to overcoming this problem is to align the probes parallel to the flow rather than parallel to the stack axis (Lundgren et al. 1978). However, this approach is based on the assumption that the swirl is constant. That assumption may not be valid if the flow rate varies and the swirl patterns change with flow rate.

\section{MODELING ASPIRATION RATIOS OF SHARP-EDGED SAMPLING PROBES}

The prediction of the aspiration ratios for sharp-edged probes has been a goal of researchers for approximatcly 40 years (e.g., Watson 1954). It is generally recognized that the important variables that must be considered are the ratio of free stream velocity to probe inlet velocity $\left(U_{\infty} / U_{i}\right)$, the angle between probe and flow stream $(\theta)$, and a parameter that reflects the inerial and fluid dynamical forces that act upon the acrosol particles, namely, the Stokes number, Stk, which is given by:

$$
S t k=\frac{C \rho_{w} D_{a}^{2} U_{\infty}}{9 \mu d_{i}}
$$


where: $C=$ Cunningham's slip correction (Fuchs 1964); $\rho_{w}=$ density of water; $D_{a}=$ aerodynamic particle diameter; $U_{\infty}=$ free stream air velocity; $\mu=$ air viscosity; and $d_{i,}=$ diameter of the probe inlet.

The general relationship between the aspiration ratio, $A$, and the independent variables of velocity ratio, $\left(U_{\infty} / U_{i}\right)$, angle $\theta$, and Stokes number, $S t k$, is (Davies 1968; Durham and Lundgren 1980):

$$
A=1+f(S t k)|R \cos \theta-1|
$$

where $R=U_{\infty} / U_{i}$ and $f(S t k)$ is a function of the Stokes number that is obtained from a combination of heuristic arguments and experimental data. Although several models have been developed for $f(S t k)$, Vincent et al. (1986) produced an expression that correlates particularly well with experimental data. A special case of their model, which represents an isoaxial sampling arrangement, is:

$$
A=1+\frac{1.05 S t k}{1+1.05 S t k}(R-1)
$$

Examples of results predicted by Eq. 6 are shown plotted in Fig. 2, where the aspiration ratio is given as a function of velocity for three particle sizes (5-, 10-, and 15- $\mu \mathrm{m}$ AED). This example assumes a flow rate of $2 \mathrm{cfm}$ through a probe that has an inlet diameter of $7.5 \mathrm{~mm}$. The probe would operate isokinetically at a free stream velocity of $21.3 \mathrm{~m} / \mathrm{s}$ and superisok netically at lower free stream velocities.

It may be noted from Fig. 2, for 10- $\mathrm{m}$ AED particles and free stream velocities of 10 to $21.3 \mathrm{~m} / \mathrm{s}$, anisokinetic effects cause the aspiration ratio to vary from approximately $75 \%$ to $100 \%$. Now, although the velocity range selected for this example is relatively large, the anisokinetic errors are not substantial. We shall show later that much larger errors are caused by wall losses in isokinetic probes, where the probes are either of the ANSI design or a design superior to that of ANSI. With respect to the sampling of gases, the Stokes number is approximately zero, so the aspiration is cinaffected by either $R$ o, $\theta$. Indeed, a probe could be placed backwards in a stack, and the aspiration ratio for gases would be unity. For gas sampling, all probe designs perform approximately the same. However, there is a need for complete mixing of contaminants and effluent air regardless of the form of the contaminant.

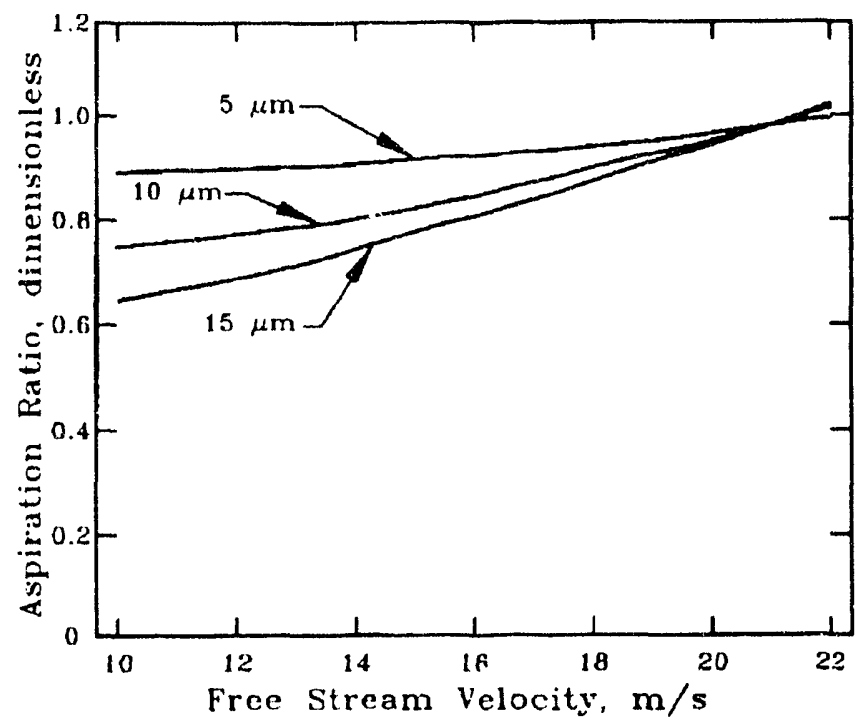

Fig. 2. Anisckinetic errors caused by changes in the free stream velocity for a probe designed to be isokinetic at $21.3 \mathrm{~m} / \mathrm{s}$ (70 ft/s). Flow rate through probe $=2 \mathrm{cfm}$, probe diameter $=7.5 \mathrm{~mm}$.

\section{WALL LOSSES IN ISOKINETIC SAMPLING PROBES}

Some organizations that set standards and regulations in the United States have adopted designs for sharpedged isokinetic probes. In the nuclear industry, emphasis is placed upon the use of probe designs that are given by ANSI (1969). Examples of designs recommended by ANSI are shown in Fig. 3, for cases of a single probe and a rake of probes. The ANSI-type probes have a constant inside diameter from the inlet through a $90^{\circ}$ bend. Because of wall losses, the performance of such probes is quite unsatisfactory.

Fan et al. (1992a) tested an ANSI-type probe in a wind tunnel to determine the wall losses as a function of wind speed and particle sizc. The probe design, Fig. 4, differed slightly from the ANSI design in that the tested unit had an internal expansion from an inlet diameter of $7.1 \mathrm{~mm}$ to a tube diameter of $9.5 \mathrm{~mm}$. This design modification causes wall losses to be smaller than those in a probe that does not have an expansion because the velocity of air in the elbow of the modified probe is lower. This produces lower inertial losses in the elbow. In the experiments of Fan et al., the modified ANSI probe was operated isokinetically over a range of wind speeds from 5 to $20 \mathrm{~m} / \mathrm{s}$ and was tested with aerosols of 5-, 10-, and 20- $\mu \mathrm{m}$ AED. As shown in Fig. 5, the wall losses 

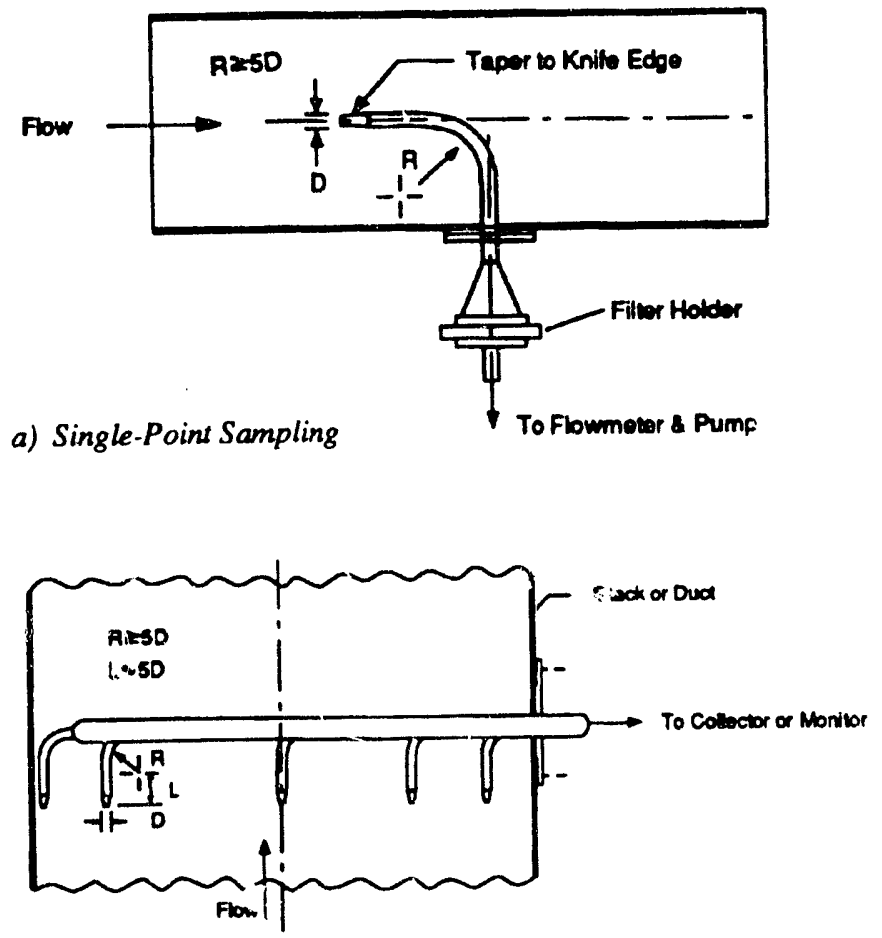

b) Multipoint Sampling

Fig. 3. Sharp-edged probes recommend od by ANSI (1969) for: (a) single-point and (b) multipoint sampling.
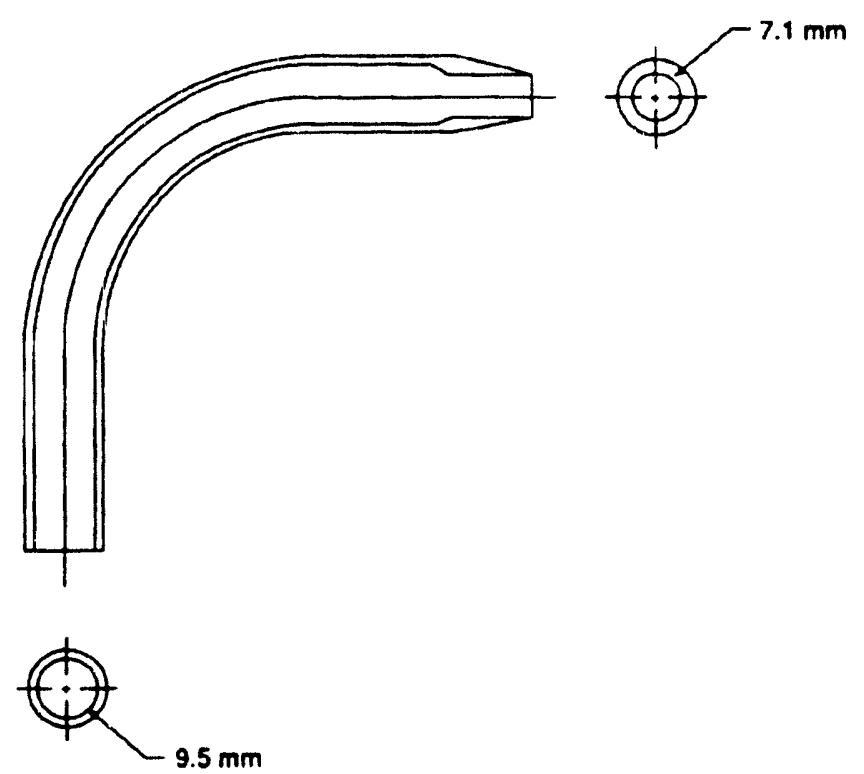

Fig. 4. An ANSI-type probe from a nuclear facility that was tested for wall losses in a wind tunnel. The probe is slightly different than the design recommended by ANSI in that the diameter expands from $7.1 \mathrm{~mm}$ at the inles $t 09.5 \mathrm{~mm}$ in the main tube. This tends to reduce the wall losses.

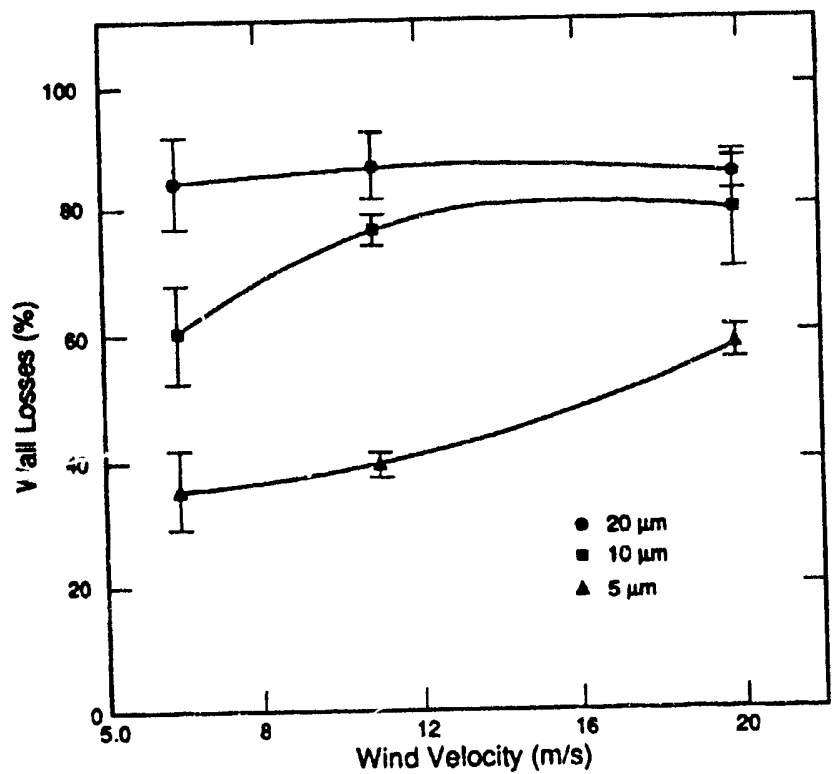

Fig. 5. Internal wall losses for isokinetic operation of the ANSI-type probe of Fig. 4. For 10-4m AED particles at a free steam velocity of $20 \mathrm{~m} / \mathrm{s}, 79 \%$ of the aerosol is lost to the walls of the probe.

corresponding to a particle size of $10-\mu \mathrm{m}$ AED varied approximately from $60 \%$ to $80 \%$ over the range of wind speeds. Thus, the transmission was only $20 \%$ to $40 \%$ for the $10-\mu \mathrm{m}$ AED aerosol. The wall losses were quantified by washing the internal walls of a probe at the completion of a test. For the experiments of Fan et al., the probe was operated isokinetically, so the aspiration ratio was unity for all data points.

Let us compare the results of Fig. 5 with those of Fig. 2 to illustrate the difference in magnitude between the typical anisokinetic errors and the wall loss errors. Because of the anisokinetic effects, $75 \%$ of $10-\mu \mathrm{m}$ AED aerosol particles enter the probe of Fig. 2 at a free stream velocity of $10 \mathrm{~m} / \mathrm{s}$. However, because of wall losses, only about $30 \%$ of the 10- $\mu \mathrm{m}$ AED particles are actually transmitted through the ANSI probe (Fig. 5) at this free stream velocity.

The results of Fan et al. clearly show the deficiencies of the ANSI-type probes and demonstrate that representative samples of aerosol particles in the inertial size range (greater than approximately $3-\mu \mathrm{m}$ AED) cannot be obtained with that design. 
The American Society of Mechanical Engineers (ASME) recommends a probe similar in design to the ANSI probes (ASME 1980). With reference to Fig. 6, the ASME probe has a constant diameter from the inlet through a $90^{\circ}$ bend. Because of the similarity of design to the ANSI probe, it is to be expected that the ASME probe would have similar wall losses. However, unlike the A.NSI probe, the majority of uses of the ASME probe are in situations that involve stack sampling for determination of compliance with non-nuclear environmental emission regulations. In such situations, wall losses can be recovered from the probe during the analysis phase of a sampling test.

In its Method 5 protocol for sampling stacks, the EPA also recommends using a probe with an elbow; however, the elbow in be exaggerated into a button hook shape (US EPA 1991c). Elder et al. (1981) investigated aerosol losses in the button hook prot, and found substantial losses just dc wnstream of the hook. Probe inlets as small as $3.2 \mathrm{~mm}$ (1/8 inch) are acceptable under Method 5, and such small inlet diameters tend to amplify inlet losses.

Williamson et al. (1987) investigated the effect of probe geometry upon the performance of source testing $\mathrm{PM}_{10}$ cyclones in simulated stack environments. Of particular interest to them were flow arrangements in which the probe inlet diameter was smaller than the diameter of the cyclone inlet tube. The probes they employed in their study had varied lengths of straight sections in the probe entrance regions and several different angles of divergence between the inlet regions and exit planes of the probes. Their data suggested that the expansion half angle should be less than $14^{\circ}$, and the straight section should be kept as short as possible.

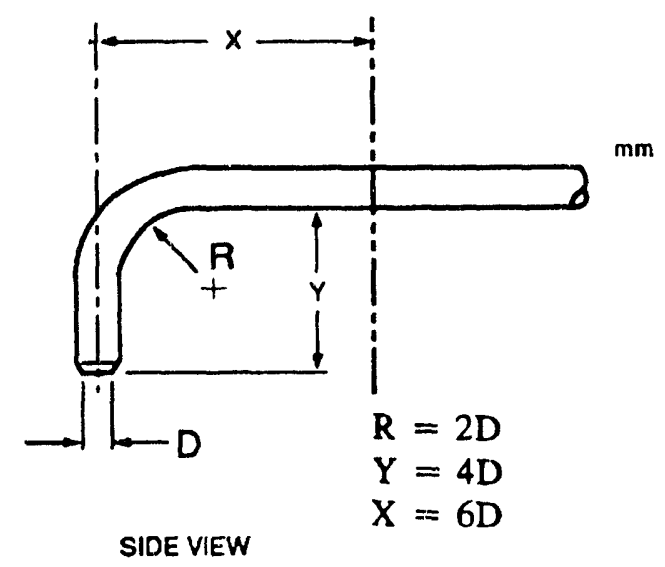

Fig. 6. Probe design recommended by ASME (1980).
Subsequently, Farthing and Dawes (1988) recommended a nozzle design (Fig. 7) for use with $\mathrm{PM}_{10}$ stack sampling cyclones that have flow rates of approximately $30 \mathrm{~L} / \mathrm{min}$. For this application, the probe must be short because the source-testing cyclone and its probe are usually inserted into a stack through a port that is approximately $150 \mathrm{~mm}$ in diameter. This problem does not arise frequently in the nuclear industry because probes are not normally attached directly to particle collection or fractionation devices. The potential for transfer of radioactive contamination to workers generally precludes the option of directly placing collection and analysis devices (CAMs, filter holders, etc.) in stacks and ducts.

Chandra (1992) conducted a study of shrouded probes that also involved testing sharp-edged isokinetic probes for comparative purposes. His isokinetic probe design, which is shown in Fig. 8, has an internal half angle of divergence of $4^{\circ}$. Wall losses in this probe are shown in Fig. 9 for a particle size of $10-\mu \mathrm{m}$ AED and a range of air

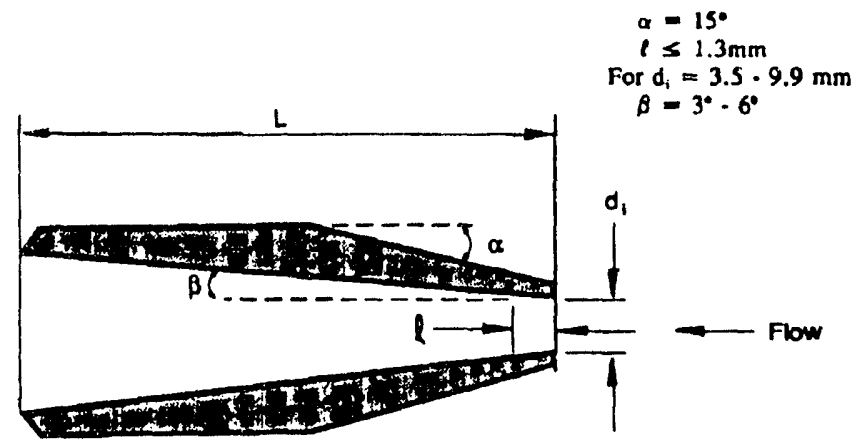

Fig. ?. Isokinetic probe design recommended by Farthing and Dawes (1988) for use with source-testing cyclones.

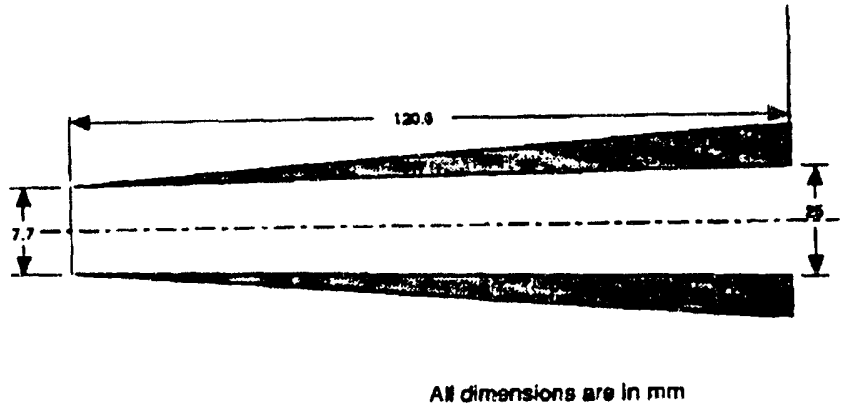

Fig. 8. Isokinel probe used as a reference by Chandra (1992). In his study, he washed the inside of the probe 10 recover the wall losses. 


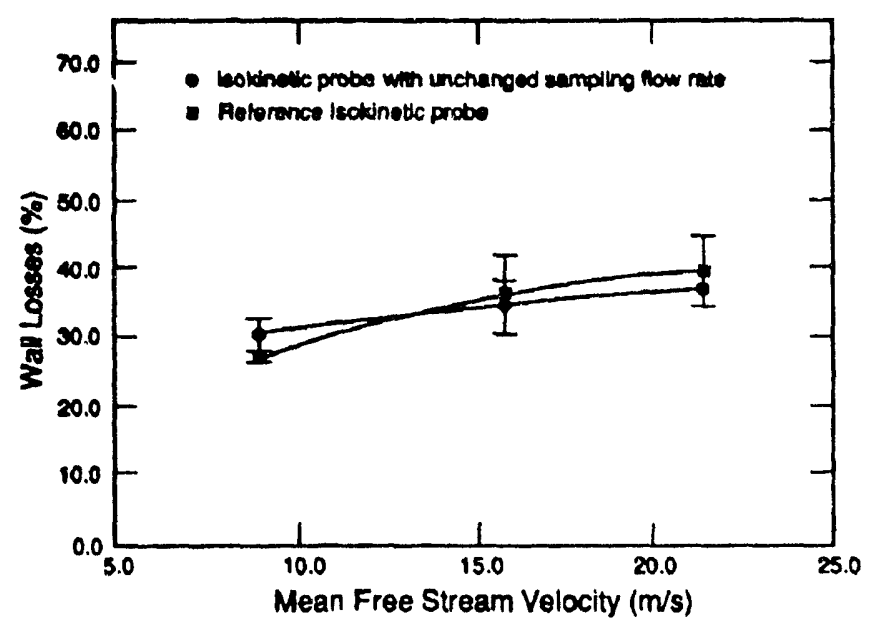

Fig. 9. Internal wall losses in the Chandra unshrouded probe. The curve marked "reference isokinetic probe" was for a probe maintained isokinetic at all free stream velocities. The other curve is for a probe operated at a constant flow rate of $57 \mathrm{~L} / \mathrm{min}(2 \mathrm{cfm})$ at all wind speeds, which provided isokinetic conditions at $21.3 \mathrm{~m} / \mathrm{s}$ and superisokinetic conditions at the lower velocities.

speeds of 8.9 to $21.3 \mathrm{~m} / \mathrm{s}$. The curve marked "Reference Isokinetic Probe" shows that the wall losses are between $32 \%$ and $38 \%$. Also shown in Fig. 9 are the results from operating an identical sharp-edged probe at a fixed flow rate in parallel with the reference probe. The probe was isokinetic at a free stream velocity of $21.3 \mathrm{~m} / \mathrm{s}$ and thus operated superisokinetically at the lower wind speeds. This situation simulates the effect upon wall losses of having a probe operated at off-design conditions. The data in Fig. 9 suggest the wall losses are approximately the same for both probes at each velocity.

Again with reference to Fig. 2, it may be noted that a Chandra-type probe, designed to operate isokinetically at $21.3 \mathrm{~m} / \mathrm{s}$, will have an aspiration ratio of $75 \%$ for 10- $\mu \mathrm{m}$ AED aerosol particles at a free stream velocity of $10 \mathrm{~m} / \mathrm{s}$; however, that probe will have wall losses of $38 \%$ (a transmission ratio of $68 \%$ ) at the same conditions. This also illustrates that wall losses can be a more serious problem than anisokinetic effects.

Wall losses in a probe occur as a natural consequence of the sampling process. Fan et al. (1992b) showed that Saffman force, which arises when aerosol particles are decelerated (or accelerated) in a shear flow, causes aerosol particles to be lost to the walls in the entrance region of a probe. This deposition mechanism is intrinsic in the sampling process because shear flows quickly develop inside a probe. Weiner et al. (1988) showed that free steam turbulence will also cause wall losses in probes. Because the flow in stacks and ducts is almost always turbulent, these losses are inevitable in a sampling process. Based on recent numerical calculations, we believe that in typical sampling situations, losses resulting from each mechanism are approximately equal.

\section{THE SHROUDED PROBE}

\section{Introduction}

Recent studies have shown that placing a shroud about the sampling probe will reduce the internal wall losses vis-a-vis those of a sharp-edged probe. Also, a shrouded probe has less sensitivity to off-design operational conditions. An example of a shrouded probe design for a sampling flow rate of $170 \mathrm{~L} / \mathrm{min}(6 \mathrm{cfm})$ is shown in Fig. 10 (McFariand et al. 1989). This system is installed at the US DOE Waste Isolation Pilot Plant (WIPP) in Carlsbad, New Mexico.

Shrouds have been used by aerodynamicists to negate angle-of-attack effects of pitot tubes mounted on aircraft. A shrouded pitot tube, called a Kiel-type probe, can be misaligned with the free stream velocity by over $40^{\circ}$ and yet give true readings (within 1\%) of the dynamic pressure (Owen and Parkhurst 1977). Torgeson and Stern (1966) used a shroud about an aerosol sampling probe on a weather reconnaissance aircraft to reduce sampling biases caused by angle-of-attack shanges in the aircraft, in which variations in the angle-of-attack result from the aircraft center of gravity shifting because of fuel consumption on flights of extended duration. The probe was connected to an inertial impactor that had a velocity requirement for the first impaction stage that was approximately $1 / 2$ that of the free stream velocity. The shroud could affect the needed velocity reduction. McFarland and Ortiz (1988) also utilized a shroud on a helicopter-borne sampler to minimize the angle-of-attack effects. That sampler was designed to collect fly ash from the plume of a large coal-fired power plant.

\section{Air Sampling with Shrouded Probes at the WIPP Site}

McFarland et al. (1989) developed the shrouded probe system that is used at the WIPP site to monitor effluent air discharged from underground disposal areas. The WIPP facility is designed to provide storage for transuranic wastes. Bedded salt at a depth of $655 \mathrm{~m}(2150 \mathrm{ft})$ below the surface of the earth has been mined to provide the 


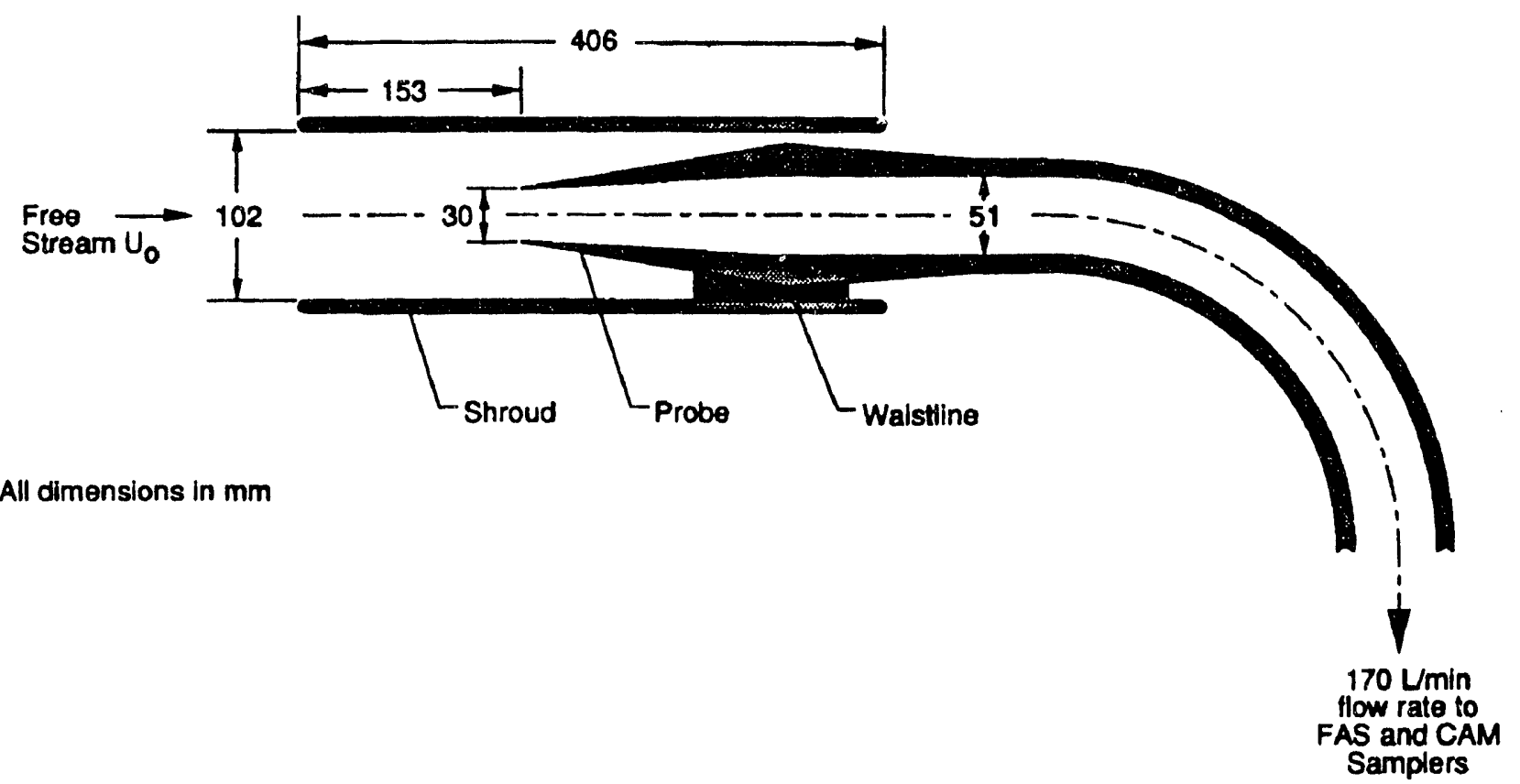

Fig. 10. Shrouded probe used for sampling in the mine ventilation exhaust ducts at the WIPP site. Flow rate $=170 \mathrm{~L} / \mathrm{min}(6 \mathrm{cfm})$. Reprinted with permission from McFarland, A.R. et al. Environmental Sci. Technol. 23: 1487-1492 (1989).

storage space. There is both vehicular traffic and human occupancy in the underground region, so the mine region is well ventilated. During normal operational conditions, the ventilation air from the mine is discharged at a flow rate of $200 \mathrm{~m}^{3} / \mathrm{s}(420,000 \mathrm{cfm})$ through a $4.3-\mathrm{m}(14-\mathrm{ft})$ diameter shaft to the atmosphere. However, in the event that one of the two main induced draft fans should either fail or be shut down, the flow rate would be reduced to $100 \mathrm{~m}^{3} / \mathrm{s}$. Also, if there were an emergency condition caused by an accidental release of radioactive particulate matter, the flow rate through the main ventilation air discharge shaft would be reduced to approximately $30 \mathrm{~m}^{3} / \mathrm{s}(60,000 \mathrm{cfm})$. In the emergency situation, the airflow would be diverted through a building that contains a bank of HEPA filters rather than be discharged directly to the atmosphere.

Sampling probes are situated at the surface elcvation in the 4.3-m diameter duct in order to detect the presence of $\alpha$-emitting acrosol particles in the ventilation air. These probes could be subjected to a range of free stream velocities from 2 to $14 \mathrm{~m} / \mathrm{s}$. However, the sampling flow rate of the probes is a constant value of $170 \mathrm{~L} / \mathrm{min}(6 \mathrm{cfm})$. Initially, the US DOE planned to place a rake of ANSI-type isokinetic probes in the $4.3-\mathrm{m}$ diameter duct and a second rake of ANSI-type probes in a $3-\mathrm{m}(10-\mathrm{ft})$ diameter duct leading from the HEPAfiltered building; however, concerns were expressed about the acceptability of such a sampling approach by the Environmental Evaluation Group of the state of New Mexico (Rodgers 1987). One concern was related to the fact that because the probes were to be operated at a fixed flow rate, the potential variation in air flow through the 4.3-m diameter ventilation duct would mean that those probes could be subjected to a velocity ratio, $R$, as small as $1 / 7$. Also, the use of six probes, as recommended by ANSI standard N13.1 for either the 4.3-m diameter duct or the 3-m diameter duct, would have meant that the probe diameters would have been small (approximately $1 / 4$ inch), and there would have been large wall losses in the probes leading to rapic. plugging by a heavy salt acrosol loading (as much as $5 \mathrm{mg} / \mathrm{m}^{3}$ ) constantly present in the effluent air.

The approach that was subsequently adopted for use in the 4.3-m diameter duct at WIPP was the employment of single-point sampling with a shrouded probe. Although the ANSI N13.1 standard specifies the number of sampling points, it does allow for fewer points if it can be shown that the acrosol concentration is uniform over 
the duct cross section at the sampling location. It was anticipated that single-point sampling would bc acceptable in the $4.3-\mathrm{m}$ duct at the surface location because the aerosol concentration and velocity profiles would be well developed on account of the presence of $0.66 \mathrm{~km}$ of straight ducting upstream of the sampling location. This length of straight pipe provides a ratio of duct length/diameter $\left(L / d_{t}\right)$ of 150 . By comparisors, Hampl et al. (1986) show that a length of approximately 50 duct diameters is needed to obtain a fully mixed condition when a contaminant is dispersed into the center of the entrance region of a straight duci in turbulent flow.

With respect to the shrouded probe application in the 3-m diameter duct that leads from the HEPA-filtered building at WIPP, it was shown through scale model testing that single-point sampling would be appropriate if there were at least 10 diameters of straight ducting upstream of the sampling location (Turner et al. 1989). Also, because the flow rate in the duct would not exceed about $30 \mathrm{~m}^{3} / \mathrm{s}$, the duct diameter could be reduced. The original discharge duct that used flow straighteners to ostensibly achieve suitable sampling conditions was then rebuilt with a $1.8-\mathrm{m}(6-\mathrm{ft})$ diameter duct that had a straight section with $L / d_{t}=11.5$ preceding the sampling location. This design was subsequently verified by ficld testing of the prototype (WIPP 1990b). Here, an $L / d_{t}$ of only 10 was needed because the flow was forced into the duct at a $45^{\circ}$ angle from a fan. That type of arrangement promotes large-scale mixing within a duct. A shrouded probe was again chosen as the single-point sampler for the HEPA-filtered building's exhausi duct. Because the anticipated velocity was $11 \mathrm{~m} / \mathrm{s}$ in that duct, the same shrouded probe design was used as that employed in the $4.3-\mathrm{m}$ duct.

\section{The Principle of Operation of a Shrouded Probe}

The principle of operation of a shrouded probe can be considered by referring to Fig. 11 . The free stream velocity, $U_{\infty}$, is decelerated upon entering the shroud to a velocity of $U_{s}$. Typically, the ratio of $U_{s} / U_{\infty}$ is about $1 / 3$, and it can be predetermined through design of the cross sectional area of the flow blockage element. Over a broad range of flow Reynolds numbers in the shroud, the velocity in the region between the blockage element and shroud internal wall, $\mathrm{U}_{f b}$, is approximately $80 \%$ of the free stream velocity (Chandra 1992). By increasing the diameter of the blockage element in a shroud of fixed inside diameter, tiie flow rate through the shroud and, correspondingly, the velocity ratio, $U_{s} / U_{\infty}$, are rediced.

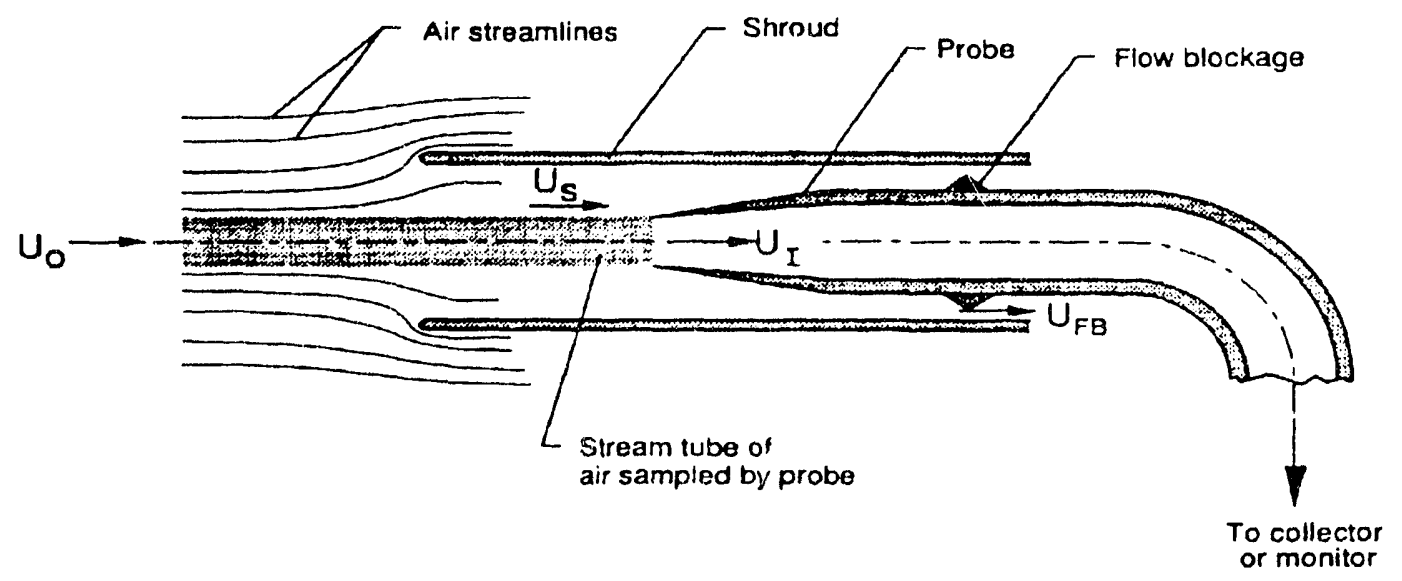

Fig. 11. Illustration of the principle of operation of a shrouded probe aerosol sampler. Anisokinetic effects take place because of curvature of streamlines. At the inlet of the shroud, the streamlines near the center are nearly straight while those near the walls are sharply curved. Because the internal probe samples only from the center of the flow field, it collects a near-representative sample, while the inertially enriched aerosol near the shroud walls is discharged through the rear of the shroud. Reprinted with permission from McFarland, A.R. et al. Environmental Sci. Technol. 23: 1487-1492 (1989). 
As the flow stream is decelerated upon entering the shroud, there is a curvature of the flow streamlines; however, the curvature is more severe in the region near the shroud walls than near the shroud centerline. This phenomenon, which is quite important, is illustrated in Fig. 12, which shows streamlines that have been calculated from computational fluid dynamics software (FIDAP 1986; Gong et al. 1993). Now the shroud is usually subisokinetic relative to the free stream, so there will usually te inertial enrichment in the shroud; but, the inertial enrichment is much more substantial near the walls of the shroud where the streamlines are more abruptly curved than in the center where the streamlines are straighter. In terms of the aspiration ratio, $A$, a model such as that of Vincent et al. (1986) correctly predicts the average aspiration for the entire shroud cross section; however, the concentration in the shroud will be anisotropic, and such a model tends to overestimate the concentration ratio in the center region of the shroud. Because the aerosol sampled by the probe is from the center region of the shroud, the potential for bias of aerosol concentration is small. Another factor that should be noted concerning the subisokinetic sampling of the shroud is that concentration bias, as reflected by the aspiration ratio, $A$, depends upon the Stokes number based upon the shroud diameter. Because the shroud diameter is relatively large, the aspiration ratio will be nearer to unity as compared with an unshrouded probe operated with similar values of the velocity ratio, $R$.

The wall losses in a shrouded probe can be expected to be less than those of an isokinetic probe in a similar application. The shroud decelerates the flow, and because the probe is designed to be operated approximately isokinetic relative to the flow inside the shroud, the velocity at the probe entrance plane will be less than that of an unshrouded isokinetic probe. Also, for a fixed sampling rate, $Q$, the diameter of the shrouded probe will be larger than that of an unshrouded probe because the shrouded probe samples air at a lower velocity than the unshrouded probe. As noted qualitatively by Durham and Lundgren (1980) or as could be ascertained quantitatively from an empirical equation of Fan et al. (1992c), wall losses in a probe increase with increasing values of velocity and with decreasing values of probe diameter. Thus, the use of a shroud about the probe reciuces the wall losses through both a lower velocity and a larger tube size compared with an unshrouded probe designed to sample isokinetically.

\section{WIND TUNNEL TESTS OF SHROUDED PROBES}

\section{WIPP Probe}

McFarland et al. (1989) tested the WIPP shrouded probe in both acrodynamic and aerosol wind tunnels. With respect to the aerodynamic tests, the shrouded

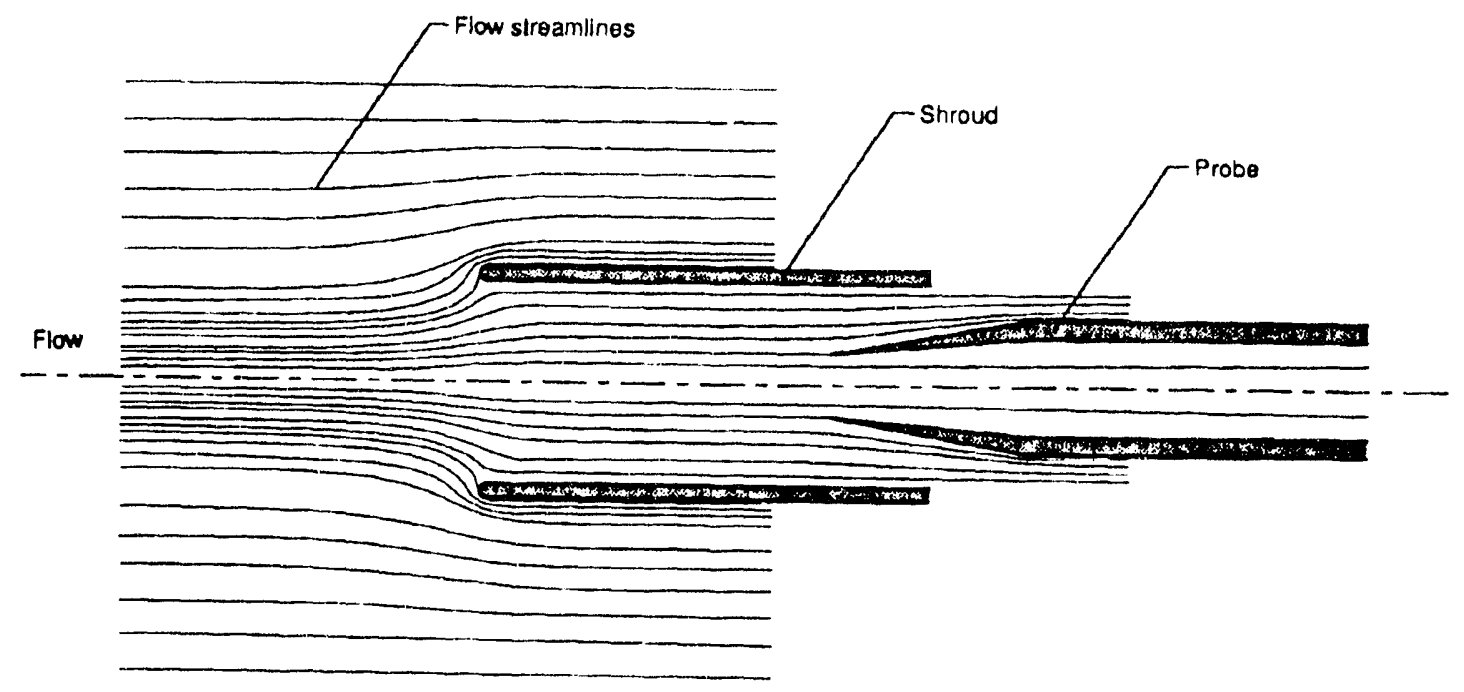

Fig. 12. Computer model of the flow streamlines in and about a shrouded probe. Shroud diameter $=51 \mathrm{~mm}(2 \mathrm{in})$, free stream velocity $=21.3 \mathrm{~m} / \mathrm{s}$, and $U_{3} / U_{-}=0.25$. Note that at the entrance of the shroud, the streamlines near the shroud walls have greater curvature than those near the center of the flow field (Gong et al. 1993). 
probe was mounted in a tunnel with a cross section of $600 \mathrm{~mm} \times 600 \mathrm{~mm}$ at the test section. A hot wire anemometer was used to obtain the velocity profiles both within and upstream of the shroud. With reference to Fig. 13, the axial component of velocity is uniform with a value of $15 \mathrm{~m} / \mathrm{s}$ upstream of the shroud. Just inside the shroud, the velocity profile shows a pattern that is nonuniform (the velocity is somewhat higher in the center region of the shroud) but does show a considerable reduction from the free stream velocity. For this probe, the mean velocity in the shroud is $38 \%$ of the free stream velocity. Within the shroud, at a distance of approximately 1 diameter downstream from the shroud inlet, the profile is quite uniform. Immediately upstream of the probe, the velocity profile shows some distortion because of the subisokinetic operation of the probe as compared with the flow in the shroud.

Tests were conducted with the ihrouded probe in an aerosol wind tunnel over a range of wind speeds and particle sizes. The effect of wind speed upon the performance of the shrouded probe in sampling $10-\mu \mathrm{m}$ AED aerosol particles over a range of velocities from 2 to $15 \mathrm{~m} / \mathrm{s}$ is shown in Fig. 14. The isokinetic probe used in

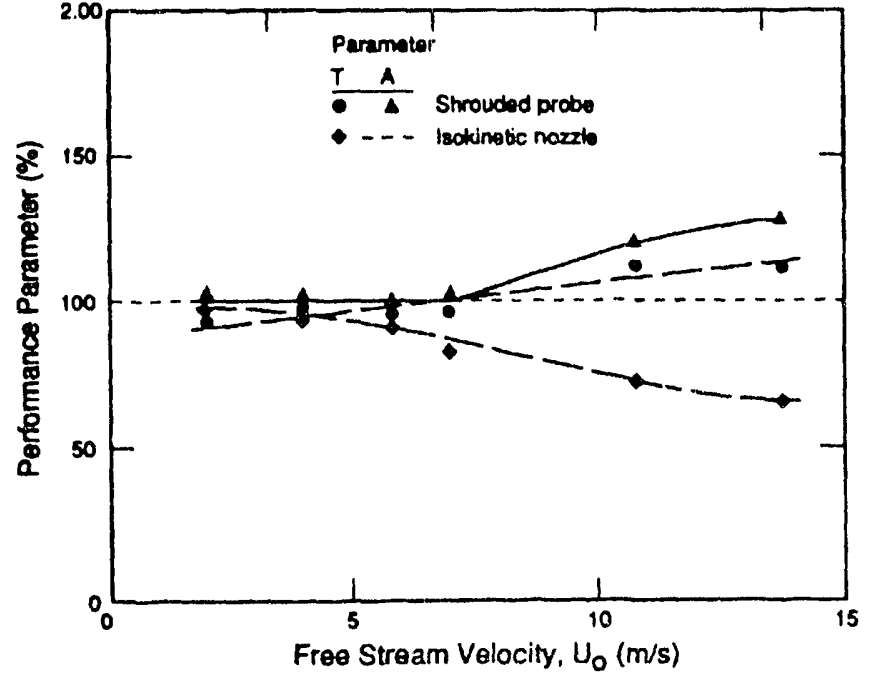

Fig. 14. Transmission ratio, $T$, and aspiration ratio, $A$, of the WIPP probe. Particle size $=10-\mu \mathrm{m}$ AED; flow rate $=170 \mathrm{~L} / \mathrm{min}$. For comparison, the transmission ratio of a co-located isokinetic probe is also shown. (MCFarland et al. 1989). Reprinted with permission from McFarland, A.R. et al. Environmental Sci. Technol. 23: 1487i192(1989).

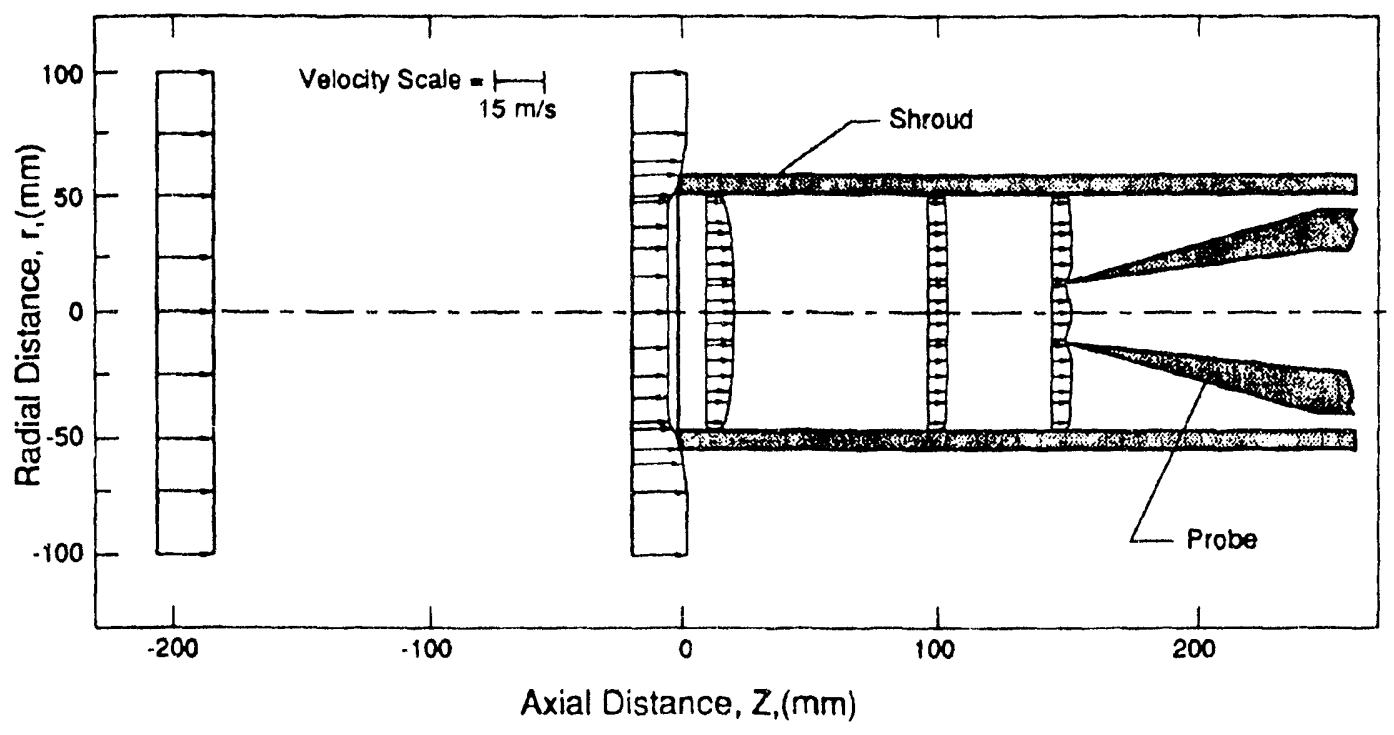

Fig. 13. Velocity profiles at various locations along the centerline of a shrouded probe. Free stream velocity $=15 \mathrm{~m} / \mathrm{s}$ and sampling flow rate $=170 \mathrm{~L} / \mathrm{min}$. (McFarland et al. 1989). Reprinted with permission from McFarland, A.R. et al. Environmental Sci. Technol. 23: 1487-1492 (1989). 
these tests was not an ANSI-type design but rather one that resembled that shown in Fig. 8. In Fig. 14, both the transmission ratio and aspiration ratio are shown for the shrouded probe while only the transmission ratio is shown for the isokinctic probe. The reason for not showing the aspiration ratio of the isokinetic probe is that the isokinetic probe was used to establish the reference concentration, $c_{\infty}$, in the wind tunnel; hence, by definition it has an aspiration ratio of unity for all velocitics. A reference concentration was determined by adding the value of acrosol concentration that penetrates through the isokinetic probe, $c_{e}$, to the equivalent concentration associated with losses recovered from the walls, $c_{w l}$ :

$$
c_{e}+c_{w l}=c_{\infty}=c_{i}
$$

It may be noted from Fig. 14 that the transmission ratio of the shrouded probe is between 0.93 and 1.11 for the range of test velocities of 2 to $14 \mathrm{~m} / \mathrm{s}$. On the other hand, because of wall losses, the transmission ratio of the isokinetic probe decreases from 0.97 to 0.63 over the same velocity range. For this shrouded probe design, the aspiration ratio varied from 0.97 to 1.26 over the velocity range. The effect of particle size upon transmission ratio and wall losses of the shrouded and isokinetic probes is shown in Fig. 15. The wall losses of this shrouded probe are about $1 / 2$ those of the unshrouded isokinctic probe. It should be emphasized that the unshrouded isokinetic probe used in these studies provides much lower wall losses than would a rake of several ANSI-type isokinetic probes, each with a much smaller inlet diameter.

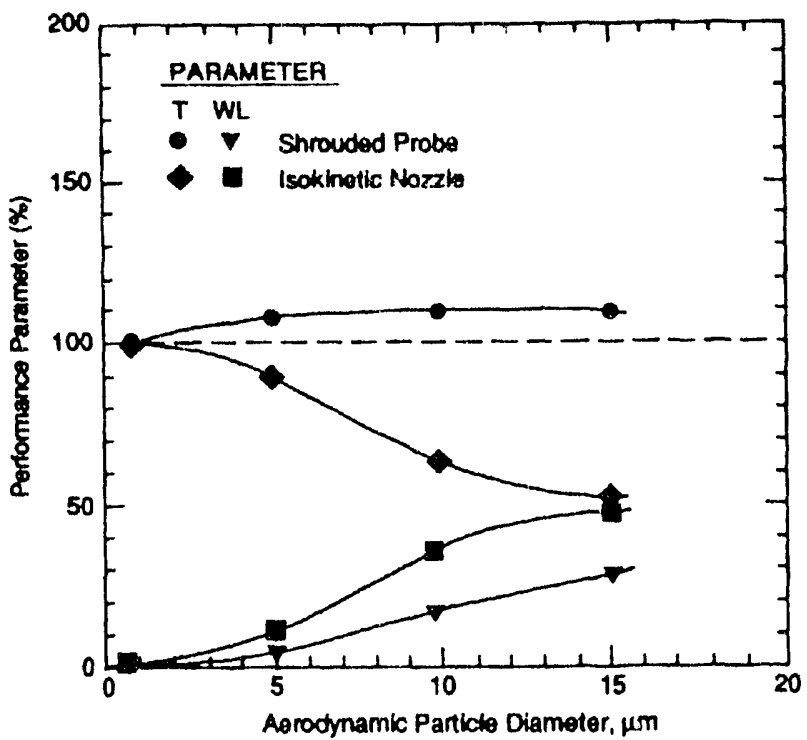

Fig. 15. Effect of particle size upon wall losses in the WIPP probe. Wind speed $=14 \mathrm{~m} / \mathrm{s}$; flow rate $=170 \mathrm{~L} / \mathrm{min}$. (McFarland et al. 1989). Reprinted with permission from McFarland, A.R. et al. Environmental Sci. Technol. 23: 1487-1492 (1989).

\section{Shrouded Probes for Lower Sampling Flow Rates}

Effects of Wind Speed and Particle Size. Chandra (1992) designed and tested shrouded probes that had nominal sampling flow rates of $57 \mathrm{~L} / \mathrm{min}\left(2 \mathrm{ft}^{3} / \mathrm{min}\right)$ and that were intended for use in stacks with velocities of less than approximately $20 \mathrm{~m} / \mathrm{s}$. The basic probe design is shown in Fig. 16. The shroud diameter used by Chandra

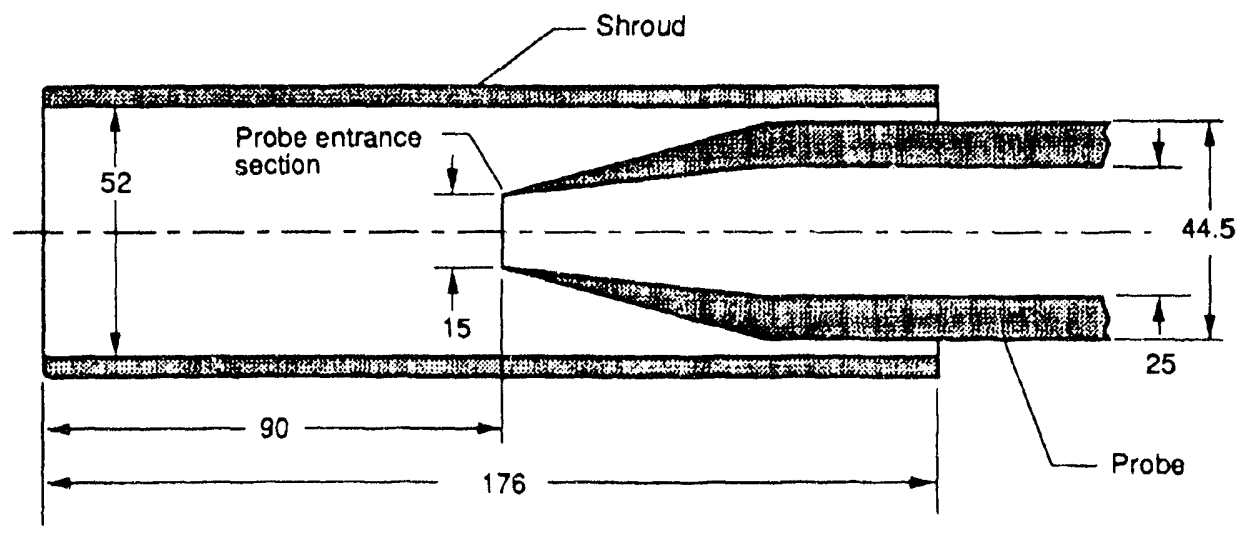

All dimensions are in $\mathrm{mm}$

Fig. 16. Shrouded probe tested by Chandra (1992) in aerodynamic and aerosol wind tunnels. The nominal flow rate through the internal probe is $56.6 \mathrm{~L} / \mathrm{min}(2 \mathrm{~cm})$. 
was $52 \mathrm{~mm}$ ( 2.0 inches), the probe diameter was $15 \mathrm{~mm}$, and the velocity ratio $\left(\mathrm{R}=U_{s} U_{\infty}\right)$ was approximately 0.25 . The probe within the shroud was designed to isokinetically sample from the air within the shroud when the free stream velocity was $21.3 \mathrm{~m} / \mathrm{s}$.

Acrosol testing of such a shrouded probe design consisted of operating an isokinetic probe and a shrouded probe in parallel in the test section of a wind tunnel. Comparisons of the wall losses in the shrouded and unshrouded (isokinetic) probes over a range of wind speeds (8.9 to $21.3 \mathrm{~m} / \mathrm{s}$ ) are shown in Figs. 17, 18, and 19 for particle sizes of 5-, 10-, and 15- $\mu \mathrm{m}$ AED, respectively. Wall losses in the shrouded probe are substantially lower than those in the isokinctic probe. For example, at a wind speed of $21.3 \mathrm{~m} / \mathrm{s}$ and a particle size of 10- $\mu \mathrm{m}$ AED, the wall losses in the isokinetic probe were $39 \%$ while those in the shrouded probe were $18 \%$. Greater differences in wall losses were generally observed at other sampling conditions.

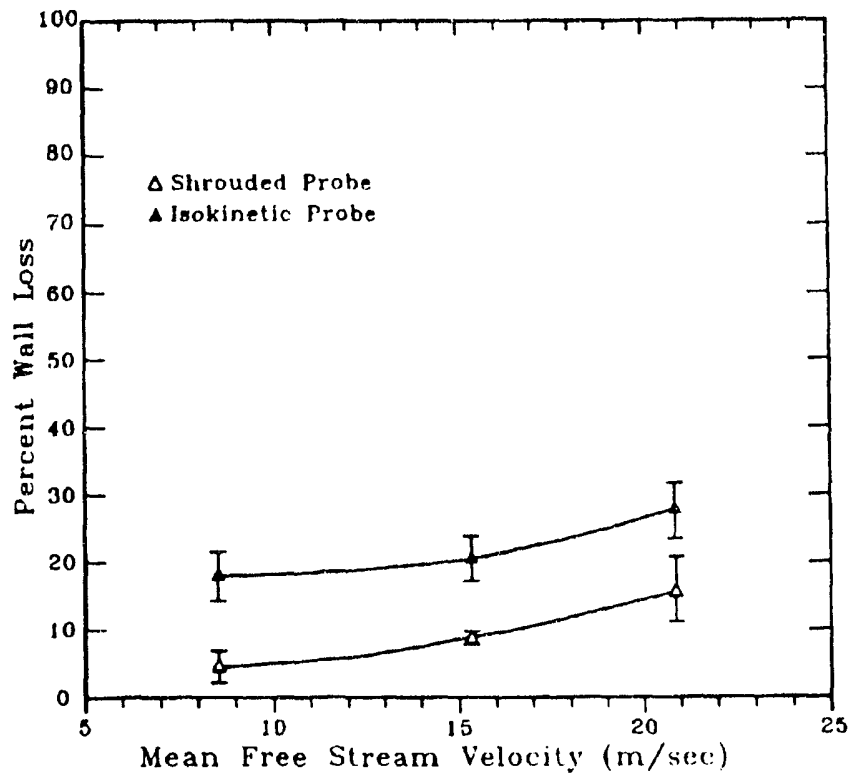

Fig. 17. Comparison of wall losses in sharp-edged isokinetic and shrouded probes for 5-4m AED aerosol particles. Flow rate $=56.6 \mathrm{~L} / \mathrm{min}(2 \mathrm{cfm})$. (Chandra 1992).

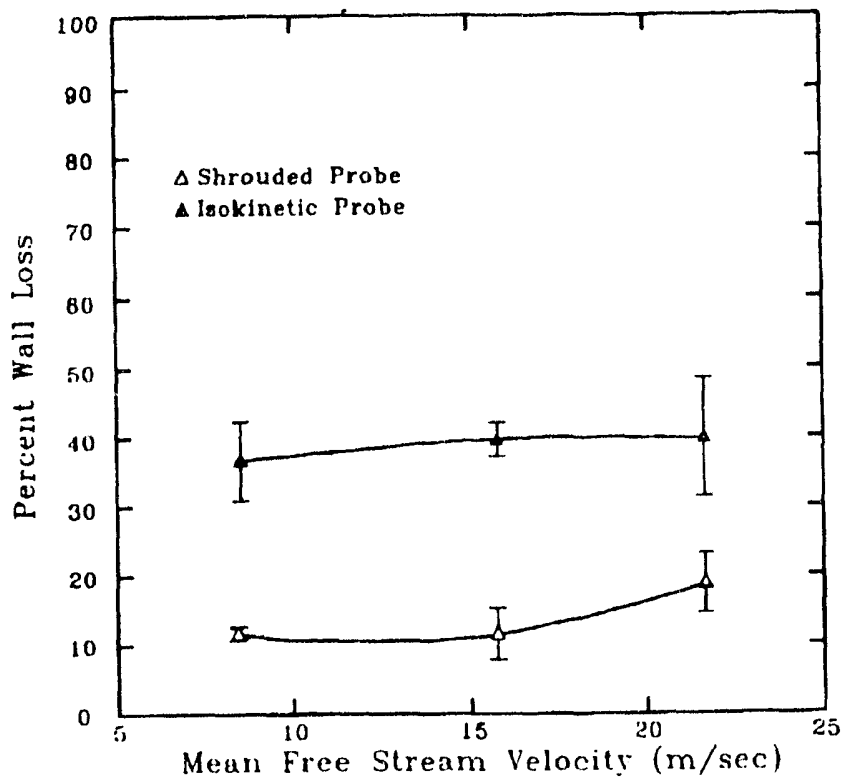

Fig. 18. Comparison of wall losses in sharp-edged isokinetic and shrouded probes for 10-4M AED acrosol particles. Flow rate $=56.6 \mathrm{~L} / \mathrm{min}(2 \mathrm{cfm})$. (Chandra 1992).

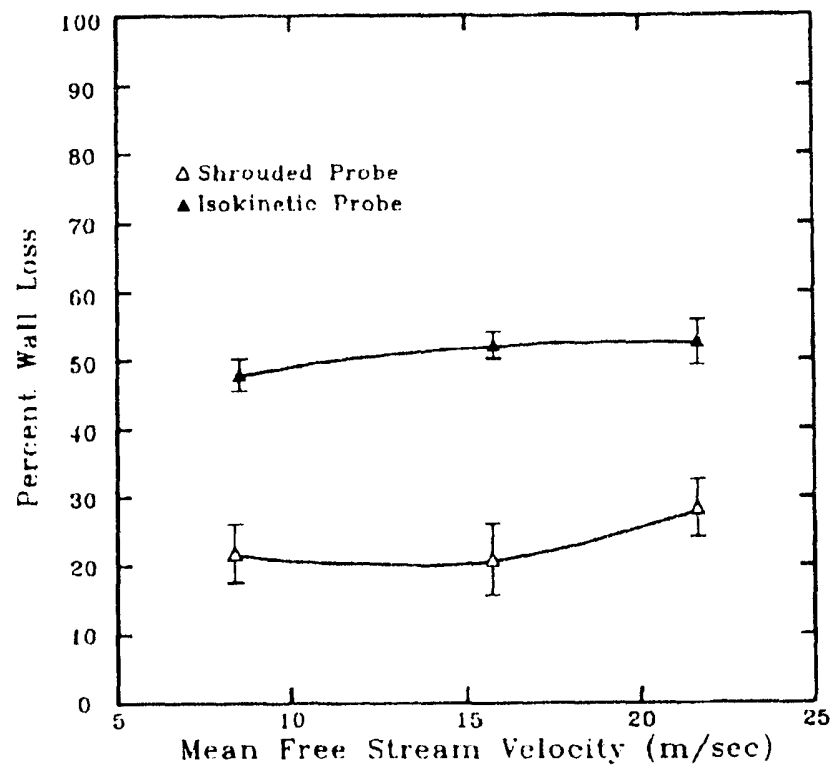

Fig. 19. Comparison of wall losses in sharp-edged isokinetic and shrouded probes for $15-\mu \mathrm{m}$ AED aerosol particles. Flow rate $=$ $56.6 \mathrm{~L} / \mathrm{min}(2 \mathrm{cfm})$. (Chandra 1992). 
Transmission ratios of the shrouded and isokinetic probes determined by Chandra for particle sizes of 5-, 10-, and 15- $\mu \mathrm{m}$ AED are shown in Figs. 20, 21, and 22, respectively. For 10- $\mu \mathrm{m}$ AED acrosol particles, the transmission ratio of the shrouded probe ranges from $83 \%$ to $88 \%$. By comparison, the transmission ratio of the isokinetic probe varies from $57 \%$ to $62 \%$.

Chandra calculated the aspiration ratio of the shrouded probe as a function of particle size and frec stream velocity. The results, Fig. 23 , show $0.88 \leq A \leq 1.15$ for particle sizes between 5- and 15- $\mu \mathrm{m}$ AED and for wind speeds of 8.9 to $21.3 \mathrm{~m} / \mathrm{s}$. By comparison, if an unshrouded probe with a fixed flow rate of $2 \mathrm{cfm}$ and a probe diameter of $8.9 \mathrm{~mm}$ were to sample over the same range of particle sizes and free stream velocities, the aspiration ratio of the isokinetic probe, as calculated from use of Eq. 6, would vary from 0.82 to 1.25 . This shows that the shrouded probe has inherently less sensitivity to off-design stack or duct velocity conditions than does an unshrouded probe.

Effect of Sample Flow Rate. An off-design sampling condition of practical interest is that related to the effect of changes in sampling rate through a probe. A reduction in flow rate below the design value could occur because of dust accumulation on the filter while sampling, and an increase in flow rate might occur if a different filter media with a lower pressure drop were to be employed. Fig. 24

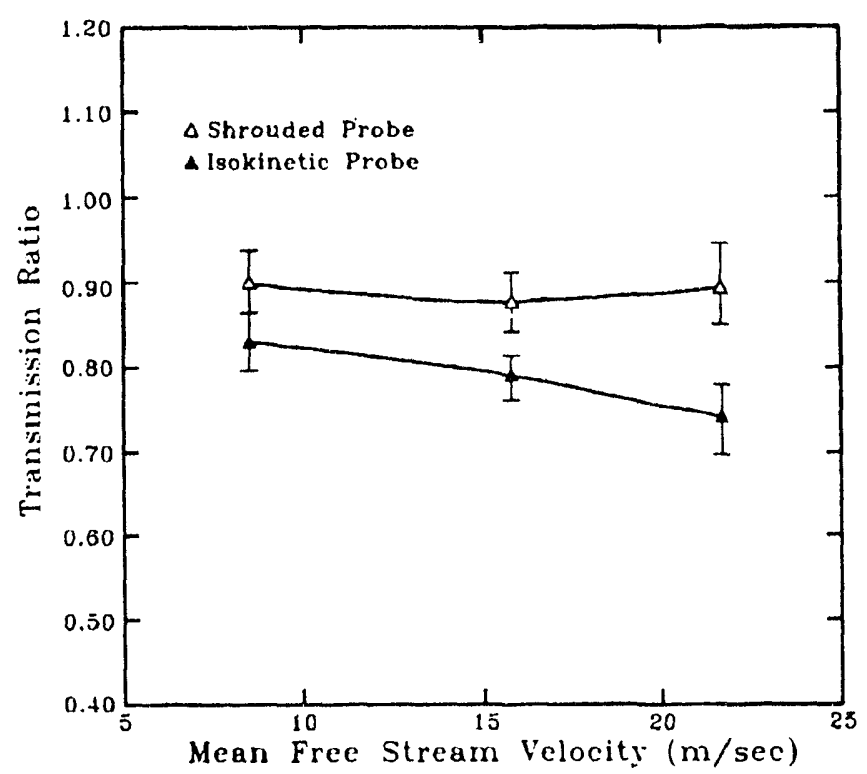

Fig. 20. Comparison of transmission ratios of sharp-edged isokinetic and shrouded probes for 5- $\mu \mathrm{m} A E D$ aerosol particles. Flow rate $=$ $56.6 \mathrm{~L} / \mathrm{min}$ (2. cfm). (Chandra 1992).

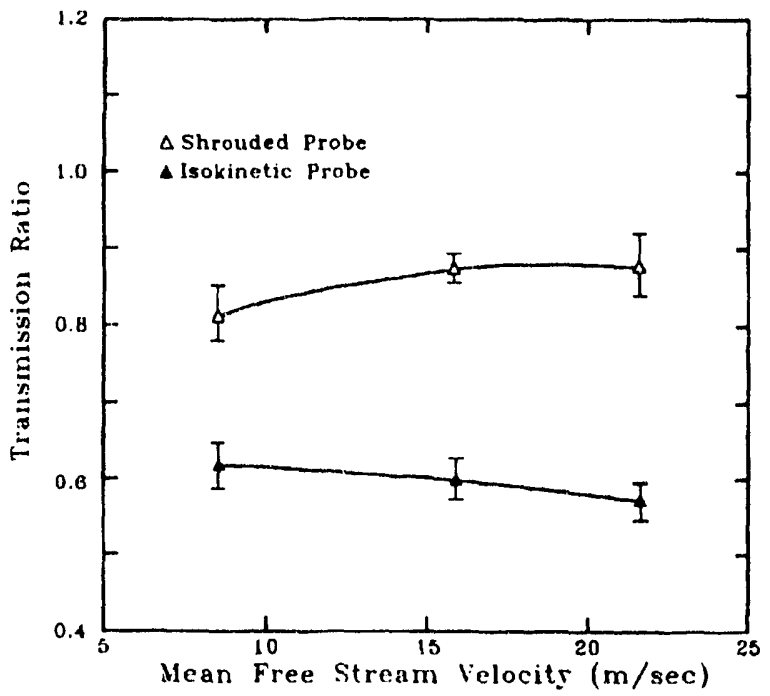

Fig. 21. Comparison of transmission ratios of sharp-edged isokinetic and shrouded probes for 10. $\mu \mathrm{m}$ AED aerosol particles. Flow rate $=56.6 \mathrm{~L} / \mathrm{min}(2 \mathrm{cfm})$. (Chandra 1992).

shows the transmission ratio for flow rates of 42,57 , and $71 \mathrm{~L} / \mathrm{min}$ through the shrouded probe system of Chandra (1992) that had been designed to operate at a nominal flow rate of $57 \mathrm{~L} / \mathrm{min}$. The data are for a free stream velocity of $21.3 \mathrm{~m} / \mathrm{s}$ and an acrosol particle size of $10 \mu \mathrm{m}$. It may be noted that $T$ only varies between 0.89 and 0.99 over the range of flow rates tested.

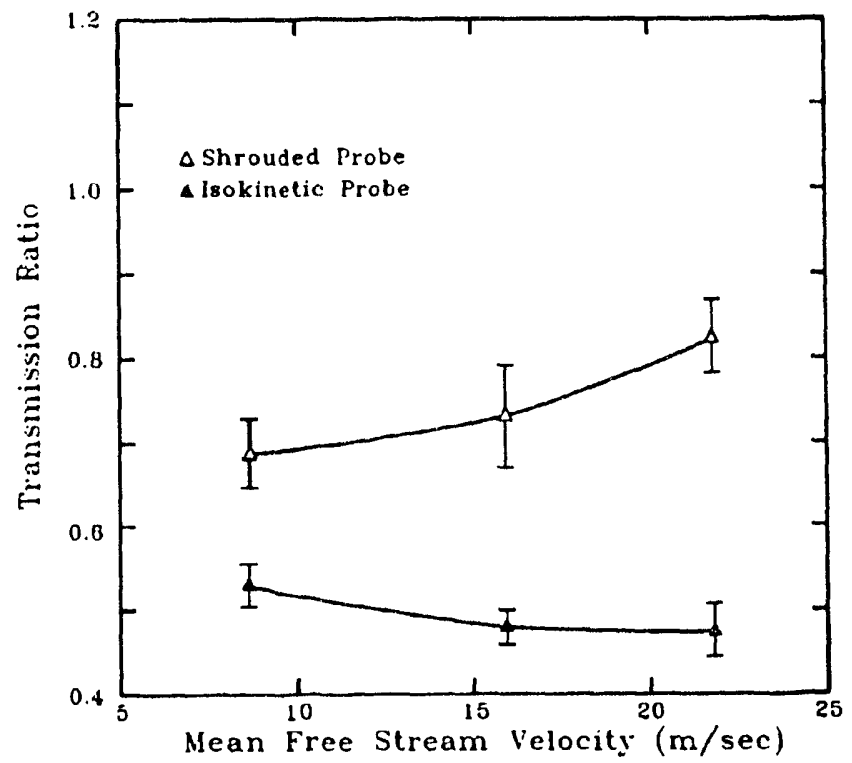

Fig. 22. Comparison of transmission ratios of sharp-edged isokinetic and shrouded probes for $15-\mu \mathrm{m} A E D$ aerosol particles. Flow rate $=56.6 \mathrm{~L} / \mathrm{min}$ (2 cfm). (Chandra 1992). 


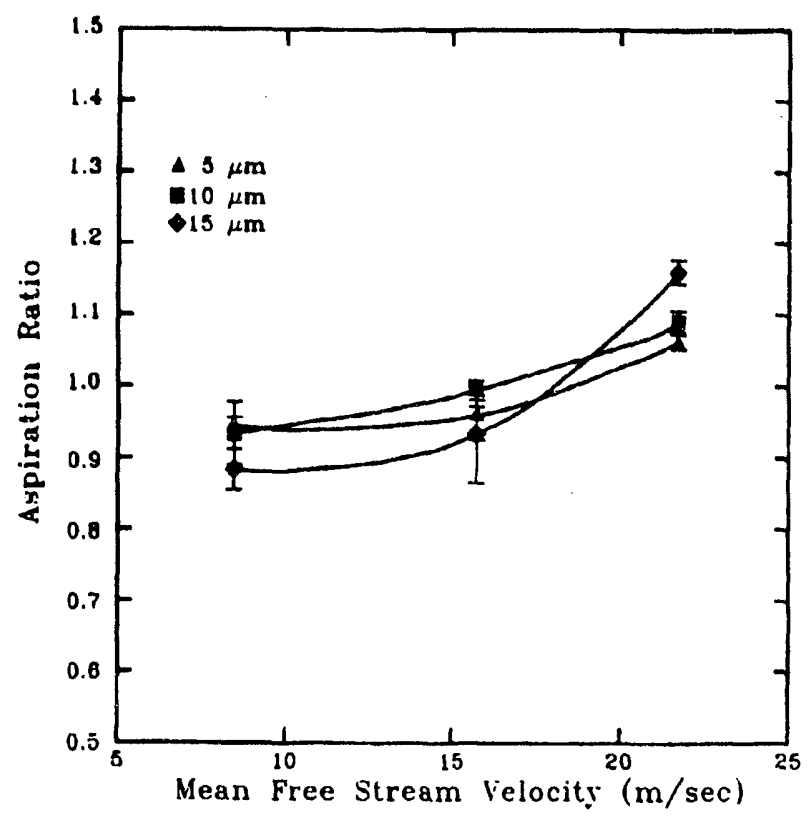

Fig. 23. Variation of aspiration ratio of a shrouded probe with free stream velocity. Flow rate $=56.6 \mathrm{~L} / \mathrm{min}(2 \mathrm{cfm})$. (Chandra 1992).

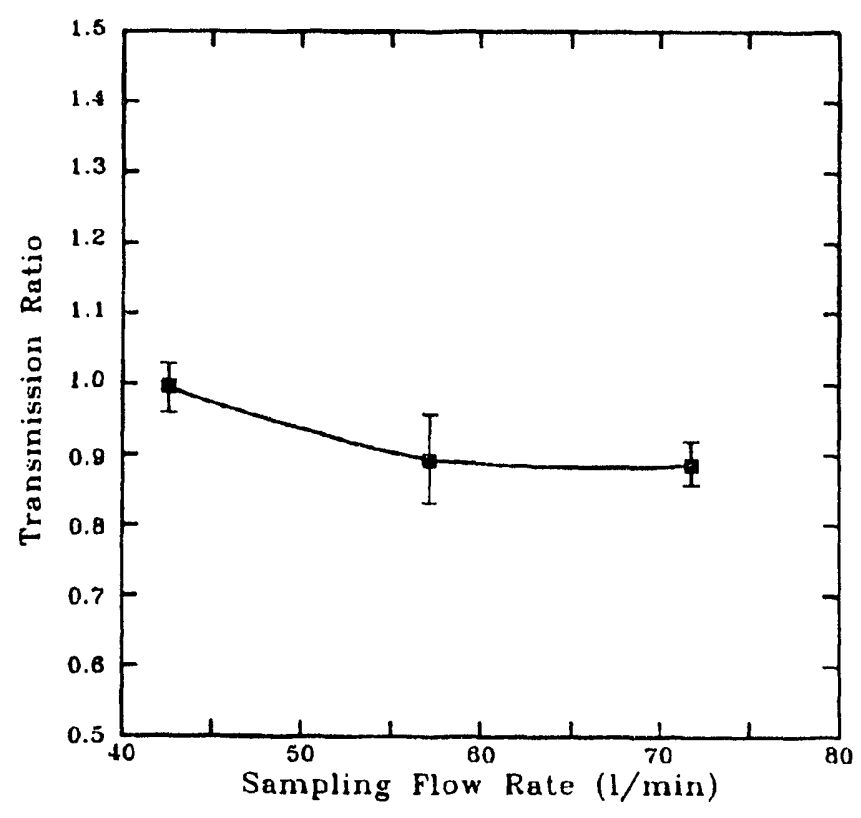

Fig. 24. Changes in the transmission ratio of a shrouded probe with variations in sampling flow rate for 10-4m AED aerosol particles. Free stream velocity $=10 \mathrm{~m} / \mathrm{s}$. (Chandra 1992).
Effect of Yaw Angle. Tests have been conducted to determine the effect on the transmission ratio of nonalignment between a probe axis and the free stream velocity vector. A 2 -cfm shrouded probe and 2 isokinetic probes were placed side-by-side in the test section of a wind tunnel. One isokinetic probe and the shrouded probe were subjected to yaw angles of $0^{\circ}-22.5^{\circ}$ while the second isokinetic probe was opereied with its axis parallel to the flow. Transmission ratio values for the misaligned isokinetic probe and the shrouded probe wrre determined by comparing the aerosol concentration measured by sampling filters placed at the exits of these probes with the concentration measured from the combination of wall deposits and filter collection of the isokinetic probe that was aligned with the flow. Tests were conducted at a wind speed of $19.3 \mathrm{~m} / \mathrm{s}$ with a particle size of 10- $\mu \mathrm{m}$ AED.

Results are shown in Fig. 25 in which the transmission ratio and $w$ all loss ratio are plotted as functions of the yaw angle. It may be noted that the transmission through the shrouded probe varied from 0.93 to 1.08 over the range of yaw angles, while that of the isokinetic probe varied from 0.54 to 0.27 . The basic reason for the better transmission of the shrouded probe relative to the isokinetic probe is because the wall losses in the isokinetic probe increase substantially with yaw angle while those of the shrouded probe do not. The wall losses in the shrouded probe are approximately constant with a value of about 0.15 while those of the isokinetic probe are 0.47 at a zero yaw angle and 0.71 at a yaw angle of $22.5^{\circ}$. Note that aspiration theory would predict that the approximate value of $A$ for both the shrouded probe and isokinetic probe would decrease from unity at a zero yaw angle to 0.92 at a yaw angle of $22.5^{\circ}$.

It is important that a sampling probe should not be susceptible to changes in performance when there are non-zero angles between the free stream velocity vector and the probe axis. Flow swirl, which will be present in some stacks under both normal conditions and under accident conditions (e.g., HEPA filter blowout), can introduce the non-zero angles as can the sampling of turbulent eddies with sizes larger than the probe diameter.

\section{Subisokinetically Operated Unshrouded Probes}

An equipment vendor that supplies air sampling systems to DOE facilities has proposed use of subisokinetically operated sharp-edged probes (Air Monitor Corp. 1993). The idea inherent in this approach 

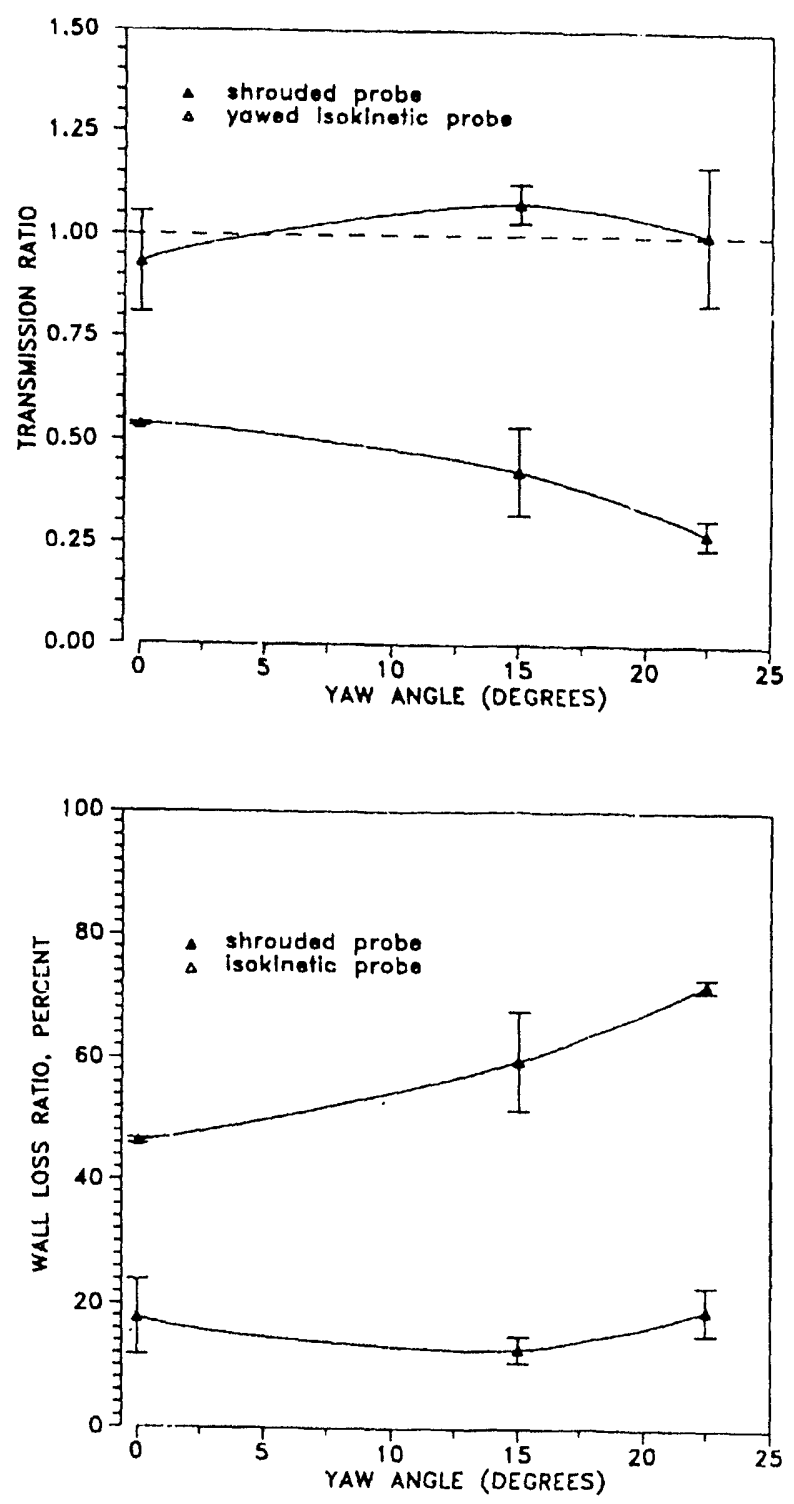

Fig. 25. Effect of yaw angle upon the performance of a shrouded and an unshrouded probe. (a) Transmission ratio. (b) Wall loss ratio. Particle size $=10-\mu m$ AED. Wind speed $=19.3 \mathrm{~m} / \mathrm{s}$. Sampling flow rate $=56.6 \mathrm{~L} / \mathrm{min}(2 \mathrm{cfm})$.

is that subisokinetic operation will increase the aspiration ratio (i.e., a subisokinetic boost), which could compensate for wall losses. A question arises about whether a subisokinetic sharp-edged probe is functionally equivalent to a shrouded probe.

A set of wind tunnel tests was conducted in which two sharp-edged unshrouded probes were tested side by side, with one probe operated isokinetically and the second operated at various degrees of subisokineticity. The wind speed in the tunnel was maintained at $19.3 \mathrm{~m} / \mathrm{s}$, so the velocity at the entrance plane of the isokinetic probe was fixed at $19.3 \mathrm{~m} / \mathrm{s}$ while the velocity at the entrance plane of the other probe was set at $5.2,10.3$, and $19.3 \mathrm{~m} / \mathrm{s}$ by adjusting the probe sampling flow rate through the range of 13.3 to $49.3 \mathrm{~L} / \mathrm{min}$. The isokinetic probe was used to establish the free stream aerosol concentration for these tests. Again, the aerosol deposited on the internal walls of the isokinetic probe was combined with that collected on an after filter to quantify the free stream aerosol concentration. Particle size for these tests was $10-\mu \mathrm{m}$ AED.

The results, Fig. 26, show the transmission ratio and wall loss ratio for the unshrouded probe over the range of velocity ratios of $1 \leq R \leq 3.7$. The transmission ratio varied from 0.65 to 1.28 and the wall losses ranged from 0.34 to 0.48 . By comparison, the data of Chandra (1992) show that for 10- $\mu \mathrm{m}$ AED aerosol particles, a shrouded probe with a fixed flow rate of $57 \mathrm{~L} / \mathrm{m}$ has a transmission ratio that varies from 0.83 to 0.88 as the velocity is varied from 8.9 to $21.3 \mathrm{~m} / \mathrm{s}$ (Fig. 21). Also, the wall losses in the shrouded probe vary from $12 \%$ to $18 \%$ over this velocity range (Fig. 18).

For a situation in which the purpose of sampling is to provide an alarm, the inertial enrichment caused by subisokinetic sampling may not be detrimental. However, the subisokinetic sampling could be performed more effectively with a shrouded probe because its wall losses are less than those of an unshrouded probe. There are two reasons the inertial enrichment effect created by subisokinetic operation of a sharp-edged probe is not a satisfactory means of obtaining record samples. First, the wall losses in the sharp-edged probe are high, which introduces uncertainty in an estimate of emissions. Second, the transmission is quite variable with the velocity ratio. Because a sampling system should be designed for emergency as well as normal conditions (ANSI 1969), and in emergency conditions there may be variations in flow rate through a stack or duct, the sensitivity of the unshrouded probe to variations in the velocity ratio would introduce additional uncertainty in the cmission estimate in comparison with the shrouded probe.

\section{FIELD TESTING OF SHROUDED PROBES}

The US DOE WIPP in Carlsbad, New Mexico, field tested the shrouded probes that were installed in both the 4.3-m (14-ft) diameter main ventilation exhaust shaft 

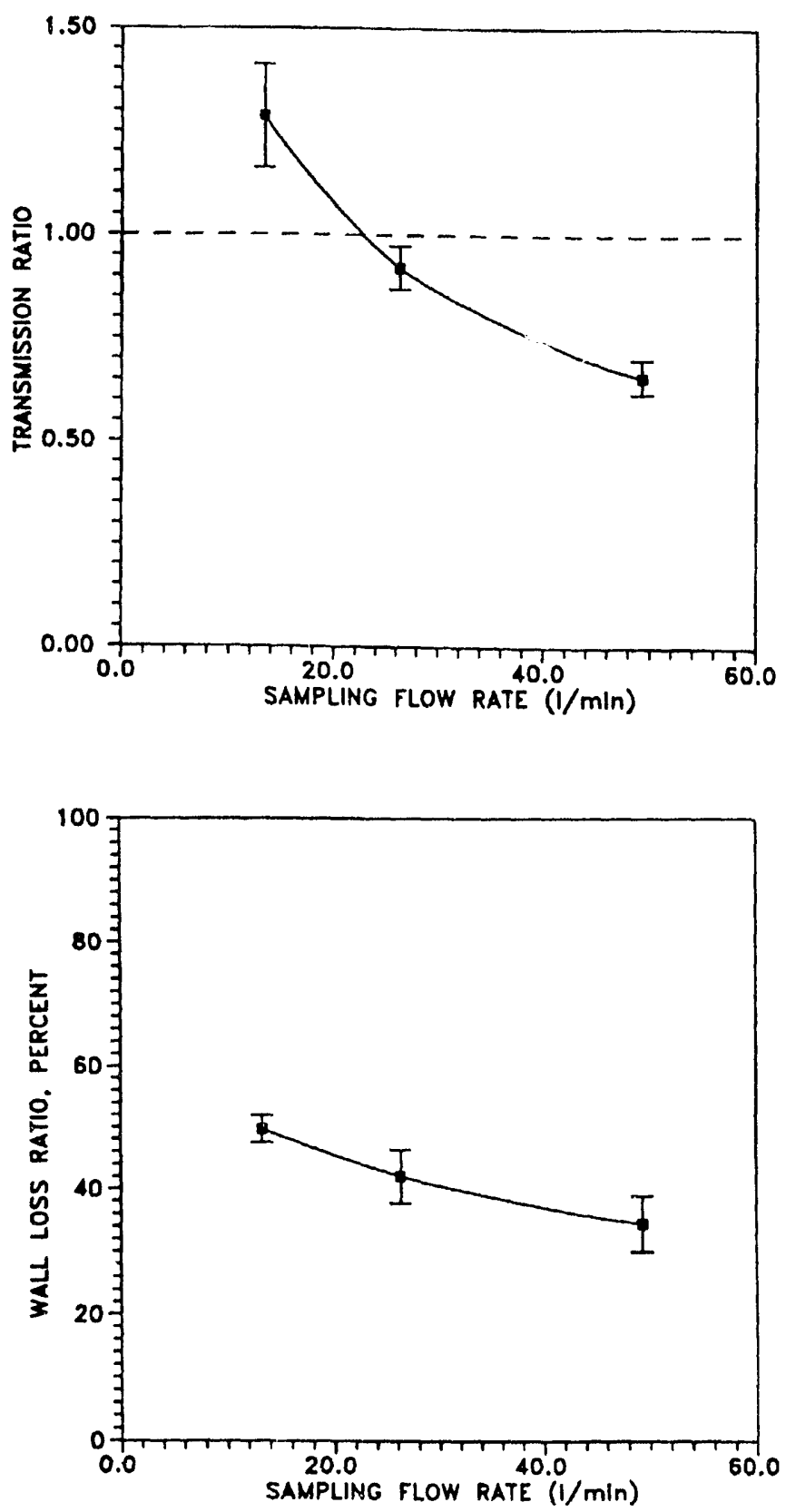

Fig. 26. Performance of a nonshrouded, sharp-edged probe operated with various degrees of subisokineticity. (a) Transmission ratio. (b) Wall loss ratio. Free stream velocity $=19.3 \mathrm{~m} / \mathrm{s}$, particle size $=10-\mu \mathrm{m} A E D$. The probe was isokinetic at a flow rate of $57 \mathrm{~L} / \mathrm{min}$ and subisokinetic for the lower flow rates.

and in the $1.8-\mathrm{m}(6-\mathrm{ft})$ diameter ducting that would discharge HEPA-filtered air into the environment if an underground accidental release of radioactivity were ito occur (WIPP 1990a; 1990b).
For tests of the sampling system in the main mineventilation duct, a salt aerosol generated with a pulverizing mill was introduced at the shaft entrance. Cascade impactors (Newton et al. 1982) fitted with isokinetic inlet probes were operated in parallel with shrouded probes at the sampling location near the surface elevation. The concentration of acrosol that penetrated the shrouded probes was not measured at the probe exit plane but rather at a location outside the flow duct (Fig. 27). Thus, the shrouded probe data reflect not only the performance of the probe but also losses of aerosol particles in the transport tubing and a three-way flow splitter at the end of each transport system. Tests were run at flow rates through the mine ventilation exhaust duct of $28 \mathrm{~m}^{3} / \mathrm{s}\left(60,000 \mathrm{ft}^{3} / \mathrm{min}\right)$ and $201 \mathrm{~m}^{3} / \mathrm{min}\left(425,000 \mathrm{ft}^{3} / \mathrm{min}\right)$. The conclusion reached by WIPP as a result of the testing program was that statistically equal values of aerosol concentration (for particles with sizes $\leq 10-\mu \mathrm{m}$ AED) were obtained for samples taken inside the ventilation duct with the inertial impactors as well as for samples taken at the exit of the aerosol transport systems of the shrouded probes. However in five of six sets of tests, the mean value of aerosol concentration determined from shrouded probe samples was greater than the mean concentration determined from the in-duct samples. WIPP (1990a) concluded that losses of particles with sizes $\leq 10-\mu \mathrm{m}$ AED through the shrouded probe and transport system were negligible. These data demonstrate that the use of a

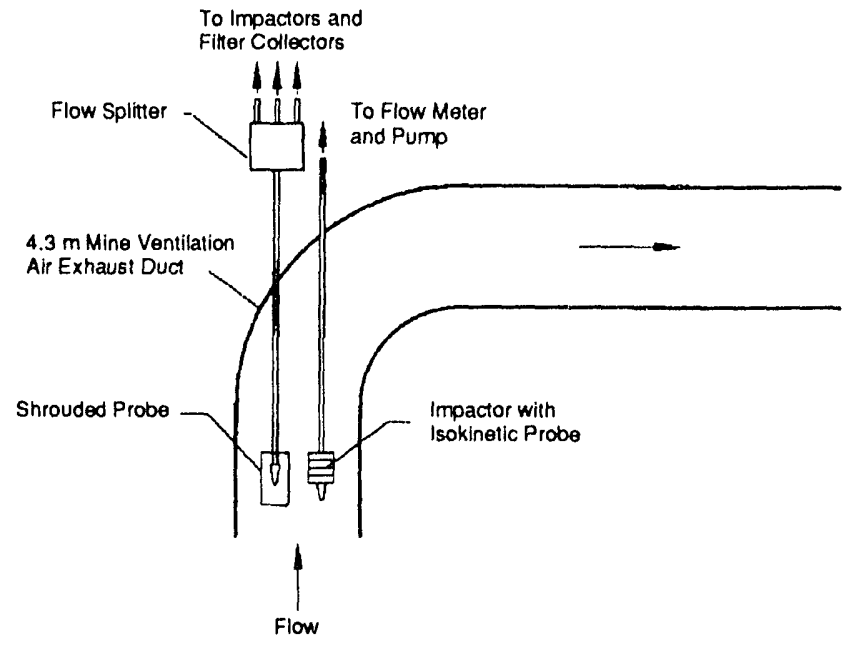

Fig. 2" Layout of apparatus used by WIPP to test the shrouded probes installed at the exit of the main mine ventilation duct. Drawing is not to scale. 
shrouded probe does not cause an underestimation of aerosol emissions; but on the contrary, may even cause a small overestimation of the concentration in the effluent air stream. Overall the shrouded probe sampler provides a much more representative sample than could be obtained by the standard methods.

The flow ducting at WIPP that leads from the HEPAfiltered building would be used during an alarm situation when the flow rate of air through the main ventilation exhaust duct would be reduced to about $30 \mathrm{~m}^{3} / \mathrm{s}$, with all of the air then being HEPA-filtered. For the tests in that duct, a salt aerosol was introduced at an upstream location in the $1.8-\mathrm{m}$ diameter flow duct. Four incrtial impactors, fitted with isokinetic nozzles, were operated in parallel with two shrouded probe sampling systems. Aerosol concentration, associated with operation of the shrouded probes, was measured at the exits of flow spitters, which were outside the flow duct. Again, for these tests the shrouded probe data reflected not only losses in the probe but in the transport system as well.

These experiment results showed also that there was no statistical difference between acrosol concentrations (sizes $\leq 10-\mu \mathrm{m}$ AED) collected inside the duct with impactors fitted with isokinetic probes and the acrosol concentrations collected outside the duct and measured with impactors connected to shrouded probes. WIPP concluded that the losses in this shrouded probe and its sampling system were negligible. The mean concentration values detected with the shrouded probe systems were larger than the mean concentration values of aerosol detected with the in-duct samplers in the two sets of tests again showing that shrouded probes do not cause an underestimation of acrosol cmissions.

It is important to note that ANSI-type probes were not used in these tests. Had they been used with the impactors in the duct, it is reasonable to expect that the concentration measured with the in-stack isokinetic probes would have been considerably smaller than that determined with the shrouded probe sampling systems.

Two shrouded probes identical to those designed and tested by Chandra (1992) have been installed in a stack on a nuclear facility at Los Alamos National Laboratory. At this time, no systematic acrosol tests have been conducted with those probes; however, during the summer of 1993, comparative stack sampling experiments will be conducted with an ANSI-type probe and a shrouded probe in one of the stacks. Monodisperse acrosols will be introduced into the stack, and the acrosol will be simultaneously sampled with the two probes.

\section{SINGLE-POINT SAMPLING}

\section{Need for Single-Point Sampling}

The wall losses in sampling probes are strongly related to the probe diameter. ANSI N13.1 (1969) recommends larger numbers of probes for larger stacks and ducts, which means that for a given sample flow rate, the standard recommends smaller-sized probes (and thence greater wall losses) for larger ducts. For stacks and ducts that meet the 8-and 2-diameter criterion, if the stack or duct is rectangular and has an area less than $0.5 \mathrm{ft}^{2}$, only 4 sampling points are recommended; however, 20 sampling points are recommended if the area is greater than $25 \mathrm{ft}^{2}$. The number of probes is not as great for circular ducts where a single probe can be used if the duct diameter is less than 6 inches. Six probes are recommended if the diameter is greater than 50 inches.

We used the model of Fan et al. (1992c) to calculate the effect of the number of sampling points on the wall losses of 10- $\mu \mathrm{m}$ AED aerosol particles. The results of these calculations are shown in Fig. 28. Here we assumed a flow rate of $56.6 \mathrm{~L} / \mathrm{min}(2 \mathrm{cfm})$ through the system and that the sampling took place isokinetically from a free stream at a velocity of $21.3 \mathrm{~m} / \mathrm{s}$. When the $2 \mathrm{cfm}$ flow rate is drawn through a single probe, the wall losses are $28 \%$; when $2 \mathrm{cfm}$ is drawn through 8 probes, the wall losses are $55 \%$; and when $2 \mathrm{cfm}$ is drawn through 20 probes, the wall losses are $73 \%$. If the sampling were done with a single shrouded probe, the wall losses would be approximately $12 \%$. We would like to emphasize that EPA Method 1 is

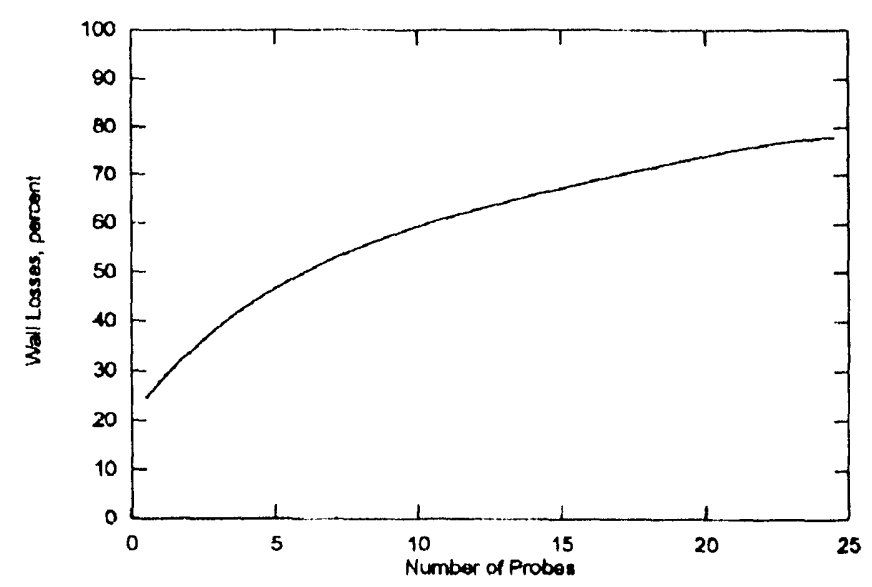

Fig. 28. Relationship between the number of isokinetic probes and wall losses. Flow rate is constant at $56.6 \mathrm{~L} / \mathrm{min}(2 \mathrm{cfm})$; free stream velocity $=21.3 \mathrm{~m} / \mathrm{s} ;$ aerosol size $=10-\mu \mathrm{m} A E D$. 
used in non-nuclear applications to specify the traverse points at which a single probe is to be sequentially situated during a stack test. Under such a situation, the wall losses for the present example would be about $28 \%$, and under the EPA Method 5 requirements, these wall losses would be recovered by washing the probe and transport line at the end of the test. For continuous monitoring as required under $40 \mathrm{CRF} 61$, Subpart $H$, the wall losses are significantly greater due to the large number of small probes, and the wall losses are not recovered.

\section{Selection of Suitable Locations for Single-Point Sainpling}

A sampling site is selected on a basis of consideration of several factors, including accessibility, expected length of transport lines, and safety, as well as a desire for the fluid momentum and contaminant mass to be well mixed. Under the 8- and 2-diameter rule given in EPA Method 1, there is an implication that good mixing is not necessary because of the use of multiple probes; however, even if multiple probes were used, better estimates of emissions could be obtained if mass and momentum were well mixed. Consider, for example, a situation in which each probe in a rake has a constan: flow rate (inlet velocity) but each is subjected to a diffeient free stream velocity concentration. When the emission estimate is based on measurements of the radioactivity collected on a single filter that is pooled from all probes, the uncertainty is greater than if the concentration and velocity were uniform.

For single-point sampling to be usable, it is essential that the fluid momentum and contaminant mass are well mixed. In some circumstances, it can be anticipated that large-scale turbulence combined with an appropriate length of ducting will provide the necessary mixing; however, it is to be expected that in many applications the flow must be engineered to enhance mixing. In the study of air sampling requirements for the WIPP facility, Turner et al. (1989) showed through the use of scale model experiments that a well-mixed flow could be obtained through the combination of a lateral flow entry into the duct (which creates large-scalc lurbulence) followed by a duct length of at least 10 diameters. Many stacks in DOE facilities have lateral entries and for some smaller diameter stacks there may be locations where the flow is already sufficiently well mixed or an appropriatc location can be created by adding a reasonable length to the stack. For example, Wood (1993) conducted a sulfur hexafluoride tracer gas mixing study at an cxisting 12-in stack at Los Alamos Nationa! Laboratory. The stack had a lateral entrance, and it had sampling stations at distances of $1.5,9$, and 14 diameters from the lateral entrance. At the 14-diameter location, the COV of velocity measurements was $7.4 \%$ and the COVs of $\mathrm{SF}_{6}$ tracer gas varied from $2.8 \%$ to $4.4 \%$ depending upon the injection location. The tracer gas was injected into the lateral duct, in the center of the stack, and along the stack wall. Although these data show that a 14-diameter location would be suitable for single-point sampling, Wood stated that the flow would be well mixed at 10 diameters where the COVs would be $\leq 0.05$.

It can be anticipated that an enhancement of mixing will be needed in many stacks in DOE facilities. If a stack is short and of large diameter, it would be expensive to add additional stack length to create a suitable singlepoint sampling location; however, mixing coulu be promoted by either modifying the ducting upstream of the stack or by inscrting mixing elements into the stack. Hampl et al. (1986) showed that mixing could be cnhanced through the use of elbows at the entrance of a duct. They obtained a well-mixed concentration profile 7 diameters downstream from a single clbow and 4 diameters downstream from a double elbow arrangement that had the axes of the two elbows in different planes. For some stacks, it may be possible to add elbows in the region between a fan and the stack or duct.

A promising approach for achicving the conditions necded for single-point sampling is to use techniques developed in the chemical engineering industry. Gas mixers have been developed for promoting chemical reactions and for reducing thermal and chemical gradients in flows. A modern gas mixer occupies a duct length of approximately 1 1/2 diameters and the flow mass and momentum are well mixed within a distance of 3 diameters of its exit plane (Tasucher and Streiff 1979; Fasano 1991).

\section{Verification of the Suitability of a Single-Point Sampling Lucation}

Criteria must be employed $t$. Jecide if a given location is suitable for single-point sampling. Besides a requirement for relative uniformity of contaminant mass and fluid momentum, the flow also must not exhibit considerable swirl. EPA has a criterion for flow 
swirl; namely, the flow angle caused by swirl will be less than $20^{\circ}$. We will use the approach given in Method 1 , Section 2.4, "Verification of the Absence of Cyclonic Flow," to determine if a candidate location meets that EPA criterion. If a significant amount of swirl is present, we will employ mixing elements in the stack or duct to remedy the problem rather than the traditional flow straighteners, because particulate stratification can accompany swirling flow, and flow mixing will not only address swirl but al'so particle stratification. As noted in Fig. 25, the performance of a shrouded probe is not degraded at yaw angles as large as $22.5^{\circ}$, so a flow that meets the EPA swirl criterion could be sampled reliably with a shrouded probe; but, we are more concerned about the effects of swirl on our ability to obtain a representative sample because of incomplete mixing rather than off-axis sampling effects.

To test for the completeness of mixing, we propose to use an approach similar to that EPA has specified for wind tunnel testing of PM-10 ambient aerosol samplers (EPA 1987). For wind tunnel applications, it is commonplace to introduce aerosol in the center of the tunnel upstream of the test section (McFarland et al. 1991). When an ambient air sampler is operated in the test section, it is important that the aerosol concentration and velocity are uniform in the region from which the sampler and reference probes can collect aerosol. Uniformity is usually achieved through use of either static mixing elements or an active mixer such as a fan. The criteria selected by EPA to characterize uniformity are that both concentration and velocity shall be within $10 \%$ of their mean values across a sampling zone. The latter term is defined as 1.2 times the inlet width of the ambient air san!pler and having a height of $0.25 \mathrm{~m}$. Here, we propose to use a criterion that the coefficients of variation of concentration of 10- $\mu \mathrm{m}$ AED liquid aerosol pariicles and a tracer gas (sulfur hexafluoride) shall be $\leq 20 \%$ across the center $2 / 3$ of the stack or duct. Similarly, the COV of the gas velocity shall be within $\pm 20 \%$ across the center 2,3 of the stack or duct. If the stack or duct is circular, the center $2 / 3$ would be defined in terms of the diameter; an $\downarrow$, if the duct or stack is rectangular in cross section, the zone of interest would be $2 / 3$ of the height and $2 / 3$ of the width of the cross section at the candidate sampling location. Note that because the velocity is zero at a wall and gradually increases in the boundary layer of a stack or duct, it is physically impossible to have a perfectly uniforai: velocity profile. Actual fully developed velocity profiles monotonically increase from the wall to the center of a duct. An ideal concentration profile will have a shape similar to the velocity profiles and will also not be perfectly uniform. To preclude the possibility of aerosol particles being trapped in the flow boundary layer, we will not allow lateral flows to enter flush with the side walls of the main flow at any location downstream of the main flow fan. A criterion will be adopted for assurance that there are no regions of anamously high concentration outside of the center $2 / 3$ of the duct. At no point on an EPA Method 1 grid of 8 to 12 sampling points shall the concentration of tracer gas or test aerosol exceed $30 \%$ of the mean concentration value.

We selected a $20 \% \mathrm{COV}$ as a criterion for uniformity rather than the absolute $10 \%$ value of EPA to reflect the reality of the difference in experimental errors between sampling from a stack or duct in the field and sampling under controlled laboratory conditions from a wind tunnel. For each stack or duct in which we seek to use single-point sampling, the uniformity of the velocity profile at the sampling location will be measured by use of EPA Methods 1 and 2 (or 2C), and the uniformity of the concentration profile will be ascertained with tracer gas and acrosol techniques. The gas tracer will be sulfur hexafluoride, and the methodology for its use will be similai to that employed by Hampl et al. (1986) and Wood (1993). The gas will be introduced at the most downstream location where radioactive aerosol particles could enter the stack or fuct. Concentration of $\mathrm{SF}_{6}$ will be measured at the traverse points specified in EPA Method 1 and in the center of circular ducts. The aerosol will be introduced into the center of the ductwork downstream of the air mover (fan). Contemporary methodology, e.g., the method used by the EPA for tests of ambient PM-10 aerosol collectors (US EPA 1987), will be used to characterize the aerosol concentration profiles. Further discussion and criteria related to representative sampling for Los Alamos National Laboraiory are given by Rodgers (1992).

\section{SUMMARY STATEMENT}

Representative sampling that faithfully shows the quality and characteristics of all constituents of the stack effluent being monitored has long been the goal of industrial hygienists and health physicists who have designed and installed monitoring equipment. Recent advances in aerosol physics have lead to a deeper understanding of the complex behavior of turbulent flows in both the stack and the sampling probe. We are in a 
strong position to recommend changes to long-standing methods in order to obtain representative samples more effectively, accurately, and reliably by bringing these advances to bear on the problem. The proposed Alternate Reference Methods represent, in our judgment, just such needed improvements in methodologies as will strengthen and support EPA's NESHAPs objectives at DOE facilities.

\section{REFERENCES}

Air Monitor Corp. (1993). Page 2 of a letter dated May 26, 1993 from P. Dave to Mr. Robinson of Battelle Pacific Northwest Laboratory. Air Monitor Corp., 1050 Hopper Ave., Santa Rosa, CA.

American National Standards Institute. (1969). Guide to sampling airborne radioactive materials in nuclear facilities. ANSI Standard N13.1-1969. New York: American National Standards Institute.

American Society of Mechanical Engineers. (1980). Determining the concentration of particulate matter in a gas stream. ANSI/ASME PTC 38-1980. New York: The American Society of Mechanical Engineers.

Chandra, S. (1992). Experimental investigation into operational characteristics of a shrouded probe for aerosol sampling. M.S. Thesis. Department of Mechanical Engineering. Texas A\&M University, College Station, TX 77843.

Davies, C.N. (1968). The entry of aerosols into sampling tubes and heads. Brit. J. Appl. Phys. Ser. 2, 1:921-930.

Durham, M.D.; Lundgren, D.A. (1980). Evaluation of aerosol aspiration efficiency as a function of Stokes number, velocity ratio and nozzle angle. J. of Aerosol Sci. 11: 179-188.

Elder, J.C.; Tillery, M.I.; Ettinger, H.J. (1981). Evaluation of EPA Method 5 probe deposition and filter media efficiency. J. Air Pollut. Contr. Assoc. 31:66-67.

Fan, B.J.; Wong, F.S.; Ortiz, C.A.; Anand, N.K.; McFarland, A.R. (1992a). Aerosol particle losses in sampling systems. Paper presented at the 22nd DOE/NRC Nuclear Air Cleaning and Treatment Conference. Denver, CO, August 24-27, 1992.
Fan, B.J.; McFarland, A.R.; Anand, N.K. (1992b). Aerosol particle losses in isokinetic sampling probe inlets. Environ. Sci. \& Technol. 26:390-394.

Fan, B.J.; Wong, F.S.; McFarland, A.R.; Anand, N.K. (1992c). Aerosol deposition in sampling probes. Accepted for publication in Aerosol Sci. and Technol.

Farthing, W.E.; Dawes, S.S. (1988). Application guide for source $\mathrm{PM}_{10}$ measurement with constant sampling rate. Report for Contract No. 68-02-442. Atmospheric Research and Exposure Assessment Laboratory, US Environmental Protection Agency, Research Triangle Park, NC.

Fasano, J.B. (1991). Kenics HEV mixer sets a new standard for turbulent mixing efficiency. Paper presented at the Mixing XII Conference, June 10-11, 1991, Banff, Alberta, Canada.

FIDAP (1986). FIDAP Package Manual, Revision 4.0, First Ed. Fluid Dynamics International, Evanston, IL.

Fuchs, N.A. (1964). The Mechanics of Aerosols. New York: The Macmillan Company.

Glissmeyer, J.A. (1992). Progress on revision to ANSI N13.1 guide to air sampling from stacks and ducts. Paper THPM-A4. Presented at the 37th Annual Health Physics Annual Mecting, Columbus, OH, June 21-25, 1992.

Gong, H.; Anand, N.K.; McFarland, A.R. (1993). Numerical prediction of the performance of a shrouded probe sampling in turbulent flow. Accepted for publication in Aerosol Science and Technology.

Hampl, V.; Niemela, R.; Shulman, S.; Bartley, D.L. (1986). Use of tracer gas technique for industrial exhaust hood efficiency evaluation - where to sample? Am. Ind. Hyg. Assoc. J. 47:281-287.

Lundgren, D.A.; Durham, M.D.; Mason, K.W. (1978). Sampling of tangential flow stream. Am. Ind. Hyg. Assoc. J. 39:640-644.

McFarland, A.R.; Ortiz, C.A. (1988). A helicopter-borne sampler for plume fly ash. Aerosol Technology Laboratory Report 5276/01/07/88/ARM; Department of Mech. Eng.; Texas A\&M Univ., College Station, TX 77843.

McFarland, A.R.; Alverez, J.L.; Hoover, M.D.; Newton, G.J.; Schmidt, A.C.; Taylor, A.O. (1992). Revisions 
being considered to ANSI N13.1: Aerosol sampling and transport. Paper THPM A-5. Presented at the 37th Health Physics Annual Meeting. Columbus, $\mathrm{OH}$. June 21-25, 1992.

McFarland, A.R.; Ortiz, C.A.; Moore, M.E.; DeOtte, R.E., Jr.; Somasundaram, S. (1989). A shrouded aerosol sampling probe. Environ. Sci.\& Technol. 23:1487-1492.

McFarland, A.R.; Wong, F.S.; Anand, N.K.; Ortiz, C.A. (1991). Aerosol penetration through a model transport system: Comparison of theory and experiment. Environmental Sci. \& Technol. 25:1573-1577.

Newton, G.J.; Carpenter, R.L.; Cheng, Y.S; Barr, E.B.; Yeh, H.C. (1982). High temperature high pressure cascade impactor design, performance and data analysis methods. J. Colloid and Interface Sci. 87:279-290.

Owen, E.; Parkhurst, R.C. (1977). The Measurement of Flow. Oxford, U.K.: Pergamon Press.

Rodgers, J.C. (1987). Exhaust stack monitoring issues at the waste isolation pilot plant. Report EEG-37; Environmental Evaluation Group. Health and Environment Department, State of New Mexico, Santa Fe, NM.

Rodgers, J.C. (1992). Representative sampling and monitoring of airborne radioactive effluent at Los Alamos National Laboratory. Report HS-DO-RAEMDP-10, Los Alamos National Laboratory, Los Alamos, NM.

Tasucher, W.A.; Strciff, F.A. (1979). Static mixing of gases. Chem. Eng. Prog. 75: 61-65.

Torgeson, W.L.; Stern, S.C. (1966). An aircraft impactor for determining the size distribution of tropospheric acrosols. J. Appl. Meteorol. 5:205-210.

Turner, W.D.; McFarland, A.R.; O'Neal, D.L.; Glass, M.G. (1989). Modeling of airflow in very large ducts. Paper 89-FE-3, New York: The American Socicty of Mechanical Engineers.

US Environmental Protection Agency. (1987). Ambient air quality standards for particulate matter; final rules. 40 CRF 53, Subpart D. Procedures for testing performance characteristics of methods for $\mathrm{PM}_{10}$. Federal Register 52:24730-24731.
US Environmental Protection Agency. (1991a). 40 CFR 61 , Subpart $H$. National emission standards for emissions of radionuclides other than radion from Department of Energy Facilities. Code of Federal Regulations. US Government Printing Office, Washington, DC 20402.

US Environmental Protection Agency. (1991b). 40 CRF 60, Appendix A. Method 1 - Sample and velocity traverses for stationary sources. Code of Federal Regulations. US Government Printing Office, Washington, DC 20402.

US Environmental Protection Agency. (1991c). 40 CFR 60, Appendix A. Method 5 -Determination of particulate emissions from stationary sources. Code of Federal Regulations. US Government Printing Office, Washington, DC 20402.

Vincent, J.H.; Stevens; D.C.; Mark D.; Marshall, M.; Smith, T.A. (1986). On the aspiration characteristics of large-diameter, thin-walled aerosol sampling probes at yaw orientations with respect to the wind. J. Aerosol Sci. 17: 211-224.

Watson, H.H. (1954). Errors due to an-isokinetic sampling of aerosols. Am. Industr. Hyg. Assoc. Quart. 15: 21-25.

Weiner, R.W.; Okazaki, K., Willeke, K. (1988). Influence of turbulence on aerosol sampling efficiency. Atmos. Environ. 22: 917-928.

Williamson, A.D.; Farthing, W.E.; Ward, T.E.; Midgett, M.R. (1987). Effects of sampling nozzles on the particle collection characteristics of inertial sizing devices. Paper 87-70.5 presented at the 80th Annual Mecting of the Air Pollution Control Association. New York: Air Pollution Control Association.

WIPP (1990a). Evaluation of the Station A effluent monitoring system in the underground exhaust ventilation system at the Waste Isolation Pilot Plant. Report DOE/WIPP 89-026. US Department of Energy, WIPP Project Office, P.O. Box 3090, Carlsbad, NM 88221.

WIPP (1990b). Evaluation of the Station B effluent monitoring system in the underground exhaust ventilation system at the Waste Isolation Pilot Plant. Report DOE/WIPP 89-027. US Department of Energy, WIPP Project Office, P.O. Box 3090, Carlsbad, NM 88221. 

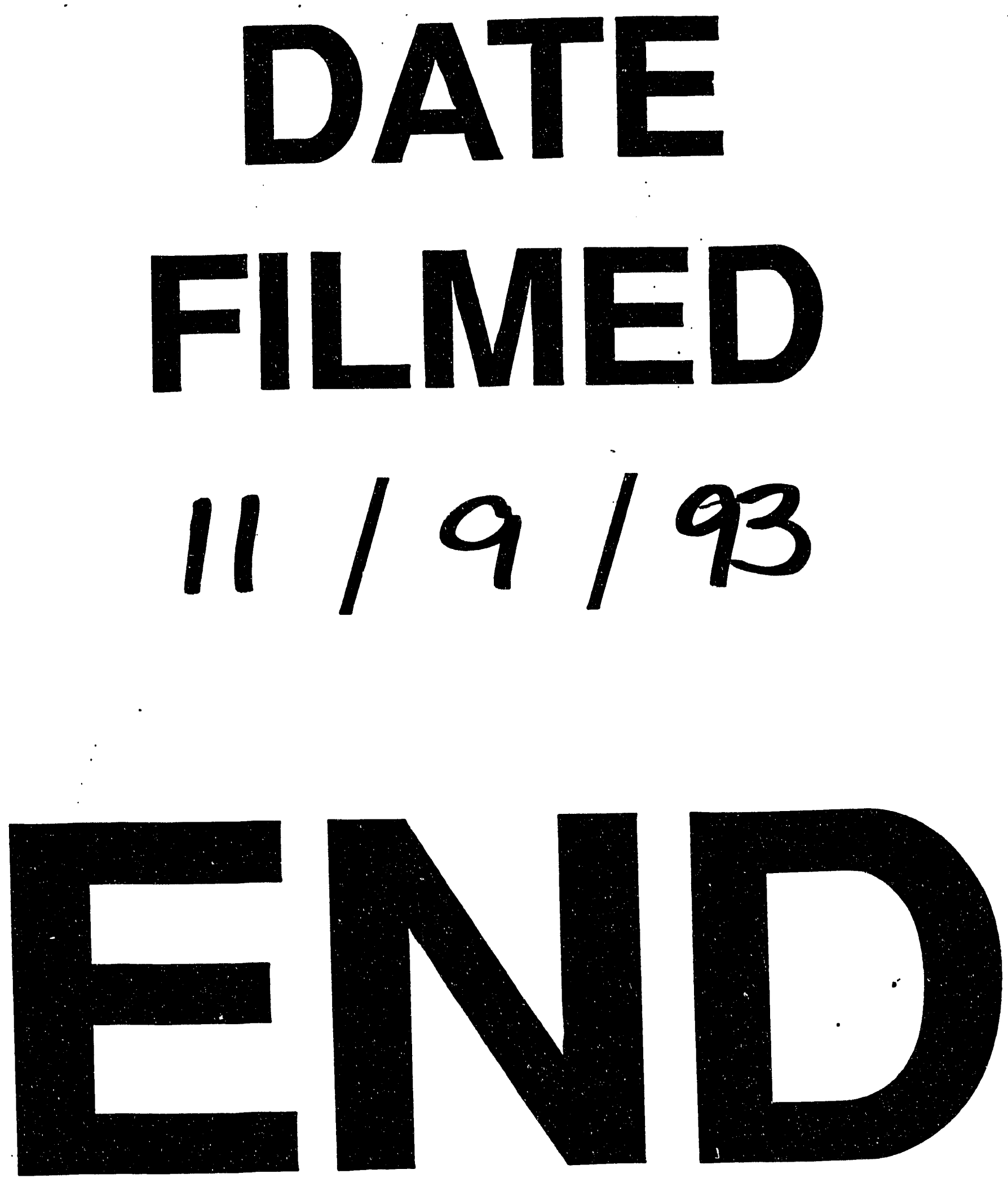


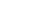

